\title{
Numerical Simulation Study of the Strata Movement Rule of Deep Mining with the Super-Thick and Weak Cementation Overburden: A Case Study in China
}

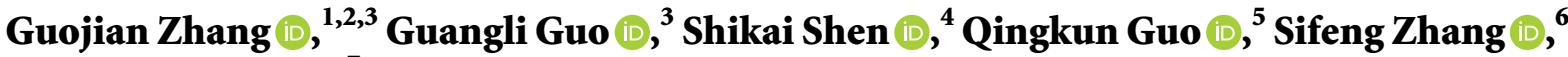 \\ and Jianfeng $\mathrm{Wu} \mathbb{B D}^{7}$ \\ ${ }^{1}$ School of Surveying and Geo-informatics, Shandong Jianzhu University, Ji'nan 250101, China \\ ${ }^{2}$ Coal Industry Engineering Research Center of Collaborative Monitoring of Mining Area's Environment and Disasters, \\ Huai'nan 232001, China \\ ${ }^{3}$ School of Environmental Science and Spatial Informatics, China University of Mining and Technology, Xuzhou 221116, China \\ ${ }^{4}$ Hydrogeology Team of Coal Geology Bureau of Hebei Province, Handan 056000, China \\ ${ }_{5}^{5}$ Jinan Institute of Surveying and Mapping, Jinan 250101, China \\ ${ }^{6}$ School of Transportation Engineering, Shandong Jianzhu University, Jinan 250101, China \\ ${ }^{7}$ Shandong Luqiao Group Co. LTD, Jinan 250101, China
}

Correspondence should be addressed to Guojian Zhang; g_j_zhang@cumt.edu.cn and Sifeng Zhang; sddxzsf@sdjzu.edu.cn

Received 7 July 2021; Accepted 8 October 2021; Published 8 November 2021

Academic Editor: Gordon Huang

Copyright (c) 2021 Guojian Zhang et al. This is an open access article distributed under the Creative Commons Attribution License, which permits unrestricted use, distribution, and reproduction in any medium, provided the original work is properly cited.

As the national energy strategy is to mine westward, the deep coal resources under the super-thick and weak cementation overburden in the western mining area will play a critical role in China's sustainable economic growth. The super-thick and weak cementation overburden has weaker lithology, thicker strata, no large joints, bedding development, and better integrity. Therefore, its movement rule is inevitably different from that of the weak overburden and the middle hard overburden in Central China and Eastern China. However, lack of studies on the movement of the super-thick and weak cementation overburden has led to severe constraints for the large-scale exploitation of coal resources under the super-thick and weak cementation overburden in the western mining area. This study explored the surface movement rule and the influence of overburden characteristics on strata movement with field measurement and numerical simulation. The findings indicate that the surface reaches full mining and the subsidence coefficient is about 0.9 when $D_{1}$ (width in the dip direction) and $D_{3}$ (length in the strike direction) are 3 times $H_{0}$ (the mean mining depth) or more. The strike mining degree has a certain influence on the surface movement law, the maximum difference of the surface subsidence coefficient is 0.35 , and the maximum difference of the horizontal movement coefficient is 0.05 . In addition, the control effect of the Zhidan group sandstone is stronger. Thus, its first breaking results in surface sinking in a fractured manner when $D_{1}$ is about 1.3 times $H_{0}$ and $D_{3}$ is 3 times $H_{0}$ or more. The above results can provide reference for the safe mining and control of the super-thick weak cementation overburden.

\section{Introduction}

The weak cementation overburden is mostly distributed in Western China, and because of the special diagenetic environment, diagenetic age, and sedimentary process, the overburden is dominated by mudstone, sandy mudstone, and glutenite. Due to their low strength, poor cementability, and easy weathering and cementation, these overburdens have been known as weak cementation strata [1]. Although the lithology of these strata is weak, its thickness is great with no large bedding and joints found. In the meantime, there is hardly any development in the folds and faults, and their integrity is generally good. All of these make their movement rule different from that of the weak overburdens and the hard strata, which are featured by stronger strength and are distributed in Central China and 
Eastern China. With the westward shift of the national economic strategy and the depletion of shallow coal resources, deep coal mining under the super-thick and weak cementation overburden is imperative. In deep mining, the process of strata movement and mine pressure behavior and surface deformation are more complicated [2]. However, the existing strata movement control theories, methods, and techniques are based on shallow mining, which are partially or entirely invalid in deep mining. These result in a significant increase in the intensity and frequency of geological disasters in deep mining [3-8]. Deep mining with super-thick and weak cementation overburden not only involves the problem of strata movement in deep mining but also is associated with the problem of the super-thick strata movement. Thus, the movement rule of the super-thick and weak cementation overburden is complex and needs to be urgently resolved.

Currently, considerable achievements of the strata movement rule in deep mining have been made. Many scholars have conducted exploratory research studies on the strata movement rule of deep mining areas with the middle hard overburden. For instance, Gao and Bai analyzed the strata movement mechanism in deep mining and believed that deep mining is characterized by small surface subsidence value, minor sinking speed, unobvious active period, and expanded influence range. In addition, the overburden sinks as a whole within a certain area [9]. Wang reviewed the related literatures and deduced that the surface subsidence rate was slowly increasing when the mining degree was small and then increased sharply when the mining degree increased to a certain value. Finally, the surface subsidence rate gradually slowed down as the mining degree increased and stopped increasing until it reached full mining [10]. Cope found that when the deep mining area was small, the surface movement is continuous, slow and long-period, and did not exist the active period [11]. Wang and Zhang demonstrated that there was a sudden change in the surface movement of deep mining. Before that point, the surface was a curved subsidence, while after that point, the surface sunk in a fracture manner [12]. Wang et al. studied the surface movement rule caused by deep multi-working face mining based on the measurement data of Zhangxiaolou mining area in Xuzhou. Their work has shown that the subsidence rate, subsidence coefficient, and mining depth indicated a logarithmic relationship [13]. Zhang found that the surface subsidence coefficient increased slowly in the extremely adequate mining, then sharply increased in inadequate mining, and finally increased in full mining [14]. Li applied physical simulation and numerical simulation methods to investigate the movement rule of the internal strata in deep mining. This study indicated that under the conditions of full mining, the subsidence coefficient of the overburden at different depths was in accordance with the power function model in deep mining [15]. Fan and Shuang employed numerical simulation to study the strata movement rule of deep mining and considered that the coupling effect between the curved zone and the fall zone had some influence on the surface subsidence [16].
Some scholars have conducted research studies on the movement rule of weak overburden in deep mining. For instance, $\mathrm{Li}$ et al. worked on the surface movement rule caused by the exploitation of deep mineral resources. The results have showed that the influence scope of deep mining expanded, and the growth rate of horizontal movement was faster than that of surface subsidence [17]. Yang studied the surface movement rule of Xiagou mine through the actual measurement. It was believed that the surface subsidence was small because of the control effect of Luohe formation sandstone and the insufficient mining [18]. Based on the measurement data of working faces 204 and 205 in Tingnan mine, Yu et al. indicated that the Luohe formation sandstone played a major role in controlling the surface subsidence [19].

From the above research studies, it can be seen that the current research on the strata movement rule in deep mining is mainly concentrated in the middle hard and hard strata, and we basically grasp its movement rule. However, the research on the deep mining of the super-thick and weak cementation overburden chiefly focuses on the characteristics and causes analysis of the strata movement in inadequate mining. Under such geological conditions, there is a lack of research on the regional strata movement rule caused by the large-scale mining.

Therefore, through on-site measurement and numerical simulation, this paper deeply analyzed the movement rule of the super-thick and weak cementation overburden caused by large-scale mining. It revealed the failure mechanism of the super-thick and weak cementation overburden in deep mining and provided a theoretical basis for deep mining with super-thick and weak cementation overburden.

\section{Analysis of the Surface Measurement Data of Deep Mining with Super-Thick and Weak Cementation Overburden}

In the deep mining area of Dongsheng coalfield, there universally exists super-thick and weak cementation overburden. We take the Yingpanhao mine in Ba'yan Chaidamu mining area of Dongsheng coalfield as an example to study the movement rule of the super-thick and weak cementation overburden. Yingpanhao mine is located in the Ordos Plateau, the middle of the Mu Us Desert, with a relatively flat terrain and beaches interspersed with sand dunes and sandy land, which are shown in Figure 1.

Most of the mine field surface is covered by modern aeolian sand and fluvial sand. The quaternary loess is exposed in sporadic areas. Based on the borehole, the strata from the old to the new are as follows: the Yanchang formation of Triassic upper system, the Yanan formation of Jurassic middle and lower system, the Zhiluo formation and Anding formation of Jurassic middle system, and the Zhidan group of Cretaceous lower system. The Quaternary upper Pleistocene system comprises the Malan formation, the residual slope, the Holocene alluvial deposits, the swamp sediments, and the aeolian sand. The stratigraphic division and coal seam conditions are detailed in Figure 2. 


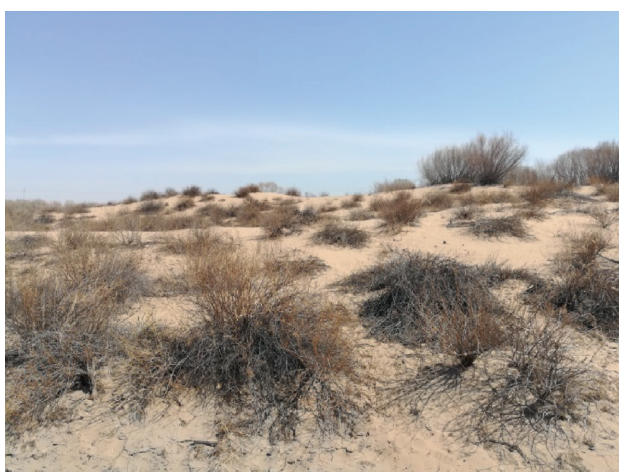

(a)

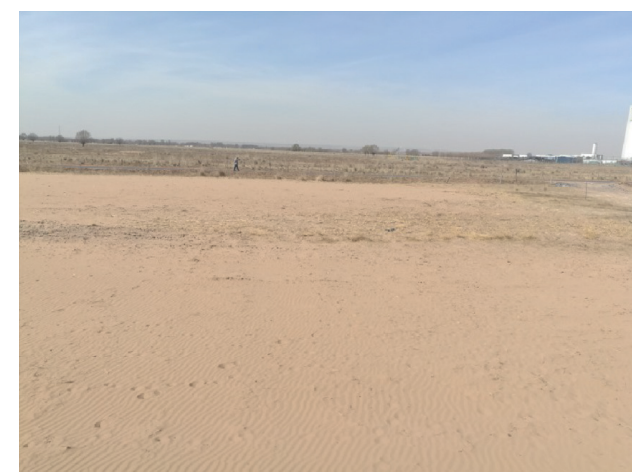

(b)

Figure 1: Landform of Yingpanhao mine.

Currently, Yingpanhao mine is mining coal seams 2-2 in the third section of the Yan'an formation, and working face 2201 of mining areas 22 and working face 2101 of mining areas 21 have been mined. The working faces 2201 and 2101 are about $300 \mathrm{~m}$ in the width and $1806 \mathrm{~m}$ and $1983 \mathrm{~m}$ in length, respectively. The coal seam is a near horizontal coal seam and about $6 \mathrm{~m}$ in thickness. The distance separated between working surfaces 2201 and 2101 is about $300 \mathrm{~m}$. To monitor the surface movement, two strike observation lines (observation lines 1 and 2) and two dip observation lines (observation lines 3 and 4) are arranged on the surface of the mining area. Due to the passage of two oil-gas pipelines in the study area, two oilgas pipeline observation lines (observation lines 5 and 6) were installed. The relative positions between the observation lines and the working faces are shown in Figure 3.

The measurement results showed that the maximum subsidence value of observation line 1 was $326 \mathrm{~mm}$, and $309 \mathrm{~mm}$ was the maximum subsidence value of observation line 2 . In addition, after investigation, we have obtained the measurement data of some deep mines near the Yingpanhao mine. For example, the surface maximum subsidence value was $520 \mathrm{~mm}$ when working face 31101 of Nalinhe- 2 mine was $1648 \mathrm{~m}$ in length. The surface maximum subsidence value was $2064 \mathrm{~mm}$ when working faces 311101, 311102, and 311103 of Ba'yan'gaole mine was mined. Based on the given data, we have inverted and compared the corresponding surface subsidence coefficient with that of deep coal mines with middle hard overburden in Eastern China such as Tangkou mine (Table 1).

In Table 1, Ba311101 Ba311103 represent working faces 311101, 311102, and 311103 in Ba'yan'gaole mine, and Y2201 denotes working face 2201 of Yingpanhao mine. T1301, T1302, T1304, T1305, T2307, T4305, and T5301 denote working faces 1301, 1302, 1304, 1305, 2307, 4305, and 5301 of Tangkou mine, T1301-1302 refer to working faces 1301 and 1302 of Tangkou mine, and so on. Based on the data in Table 1, the diagram of mining degree and surface subsidence coefficient in Eastern China and Western China was drawn (Figure 4). It can be seen from Figure 4 that under the same mining degree, the surface subsidence coefficient of the superthick and weak cementation overburden mining is clearly small. The surface of the super-thick and weak cementation overburden still exhibits the characteristics of extremely inadequate mining when the surface of the deep mine with middle hard overburden in Eastern China is close to full mining, and it takes more mining space to achieve full mining.

Based on the measurement data and the synthetic histogram of mining area 22 (Figure 2), it is preliminarily concluded that the 300-meter-thick Zhidan group sandstone and the 120-meter-thick Zhiluo formation sandstone show a strong control effect, which can effectively hinder the strata moving upward to the surface. We call it Guess 1. The large thickness and no large joint development make their overall stiffness high. In Sections 3, 4, and 5 the space-time evolution rule of the overburden movement in the case of deep multiworking face mining with super-thick and weak cementation overburden was investigated, and the role of thick sandstone structure in the process of the overburden movement was discussed by physical simulation and numerical simulation.

\section{Strata Movement and Energy-Polling in the Super-Thick and Weak Cementation Overburden}

To study the movement rule of the super-thick and weak cementation overburden in the case of large-scale mining, the initial three-dimensional numerical model was established based on the synthetic histogram of mining area 22 in Yingpanhao mine (in Table 2). The model was $4075 \mathrm{~m}$ in length, $4000 \mathrm{~m}$ in width, and $763 \mathrm{~m}$ in height. The constitutive model of this numerical model was the Mohr-Coulomb Model. The mechanical parameters of the strata in the model were determined from the mechanics experiment of the rock mass in the laboratory. The bottom boundary of the model was determined as $u=v=w=0$ ( $u$ was the displacement in the $x$ direction, $v$ was the displacement in the $y$ direction, and $w$ was the displacement in the $z$ direction). The top was the free boundary, and the left and right boundaries were fixed in the horizontal displacement.

3.1. Strata Movement Rule of the Super-Thick and Weak Cementation Overburden. To check the reliability of the model, we mined two working faces based on the actual 


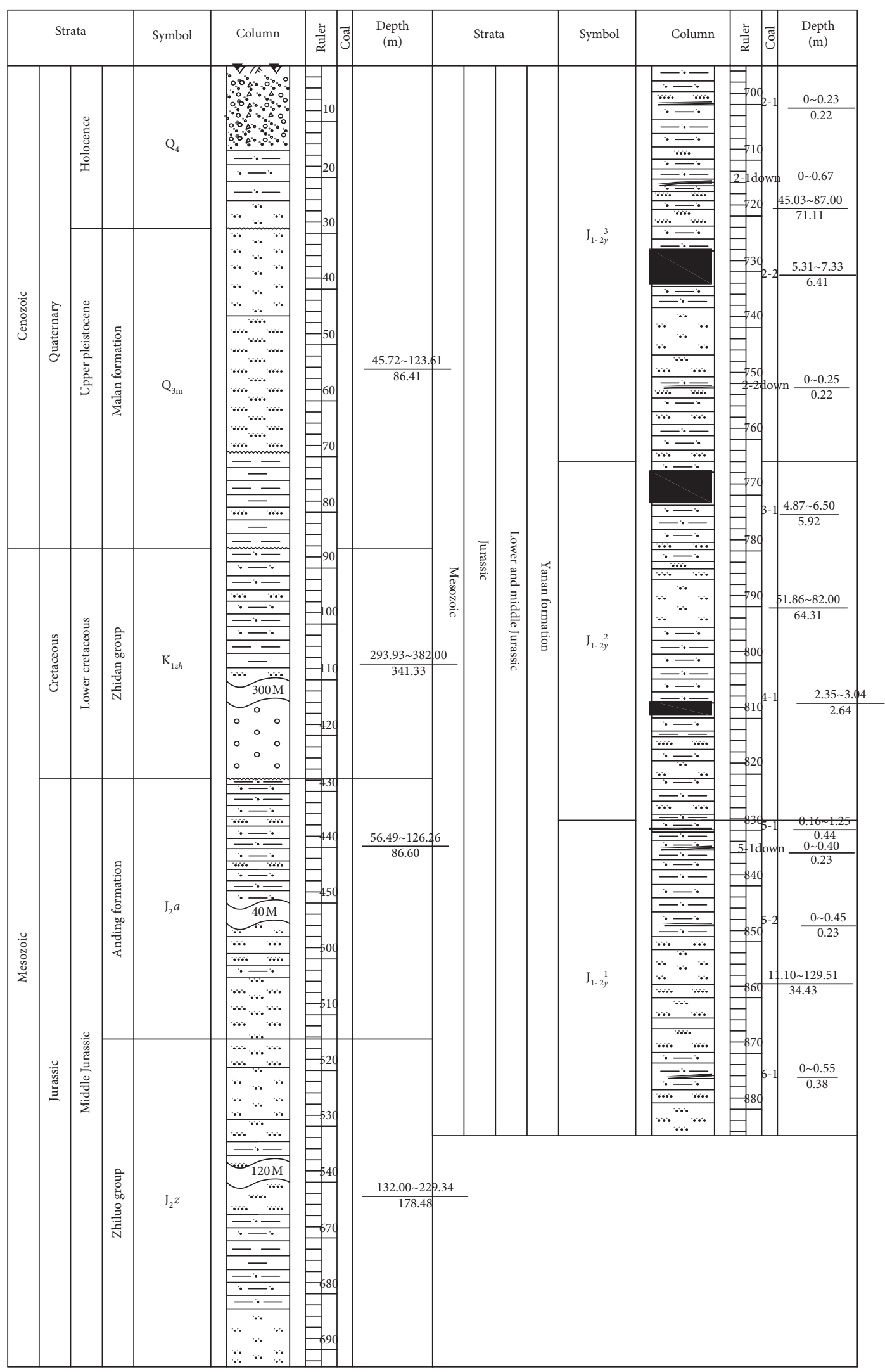

FIGURE 2: Synthetic histogram of mining area 22. 


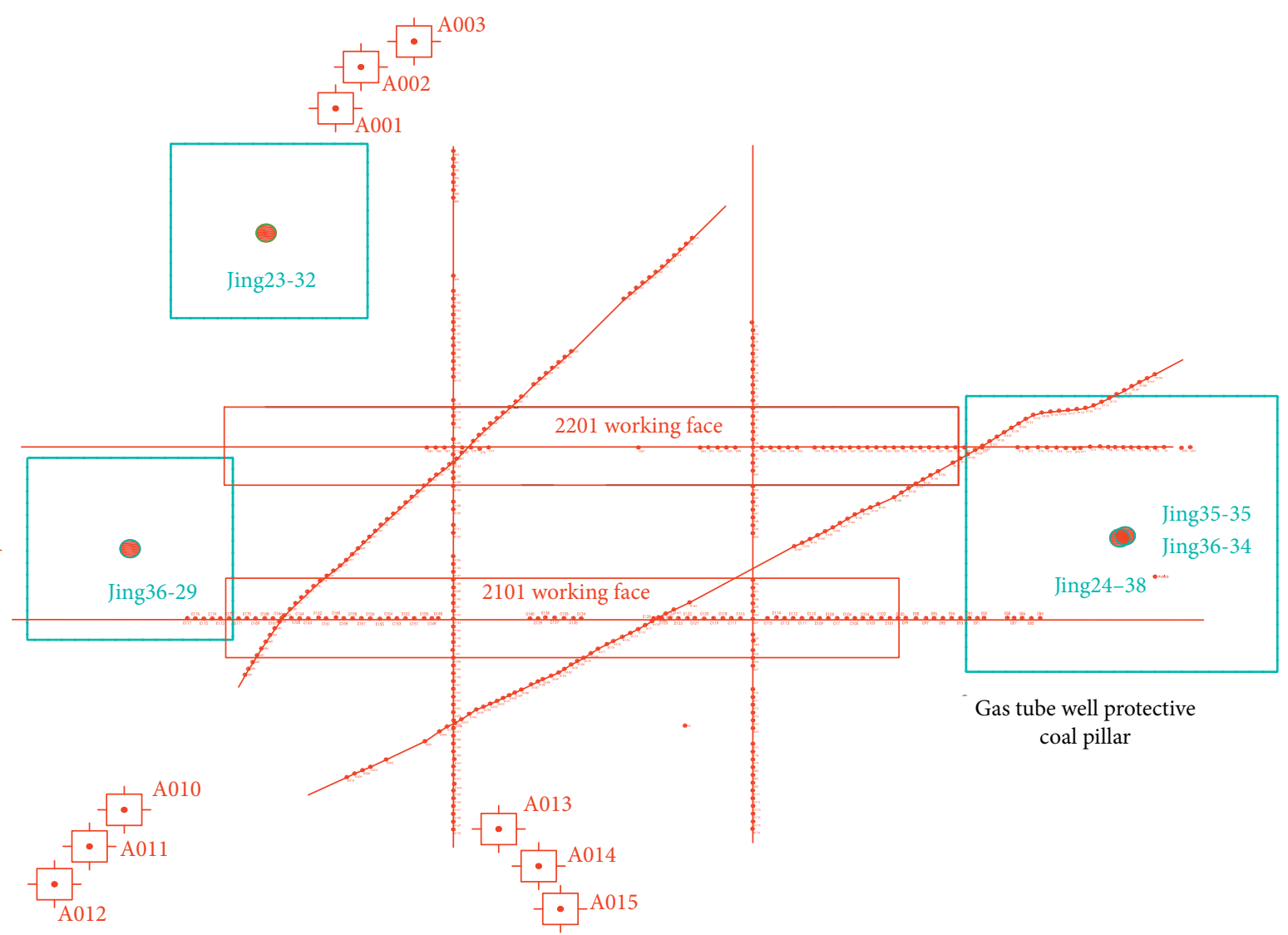

FIGURE 3: Relative positions of observation line and working faces.

Table 1: Goaf parameters of deep coal mine.

\begin{tabular}{|c|c|c|c|c|c|c|}
\hline Working face & $\begin{array}{c}\text { Mining } \\
\text { Width (m) }\end{array}$ & $\begin{array}{l}\text { Advancing } \\
\text { Length (m) }\end{array}$ & $\begin{array}{c}\text { Mining } \\
\text { Height }(\mathrm{m})\end{array}$ & $\begin{array}{c}\text { Mining } \\
\text { Depth (m) }\end{array}$ & Loose $(\mathrm{m})$ & Bedrock ply (m) \\
\hline $\mathrm{Ba} 311101 \sim \mathrm{Ba} 311103$ & 810 & 2600 & 5.3 & 650 & 118 & 532 \\
\hline $\mathrm{Na} 31101$ & 240 & 3030 & 5.5 & 650 & 78 & 572 \\
\hline Y2201 & 300 & 1800 & 6.0 & 725 & 45 & 680 \\
\hline $\mathrm{T} 1302$ & 210 & 1560 & 3.6 & 960 & 212 & 748 \\
\hline $\mathrm{T} 1301$ & 215 & 1320 & 3.4 & 1000 & 212 & 788 \\
\hline $\mathrm{T} 1301 \sim \mathrm{T} 1302$ & 420 & 1440 & 3.5 & 1000 & 212 & 788 \\
\hline T1304 & 150 & 1457 & 4.9 & 910 & 212 & 698 \\
\hline $\mathrm{T} 1305$ & 130 & 1540 & 4.9 & 920 & 212 & 708 \\
\hline $\mathrm{T} 2307$ & 210 & 1320 & 3.6 & 865 & 212 & 653 \\
\hline $\mathrm{T} 4305$ & 120 & 1255 & 3.1 & 1040 & 212 & 828 \\
\hline $\mathrm{T} 2307 \sim \mathrm{T} 2310$ & 825 & 1263 & 4.1 & 825 & 212 & 613 \\
\hline T5301 T5303 & 510 & 1541 & 4.8 & 965 & 212 & 753 \\
\hline
\end{tabular}

situation of Yingpanhao mine. The working face was $300 \mathrm{~m}$ in width and $2000 \mathrm{~m}$ in length, and the two working faces were separated by the 300-meter-wide coal pillar. Based on the simulation results, three-dimensional contour map of surface subsidence was drawn (Figure 5). Based on the measurement results of the surface, the subsidence of Point C52 was $326 \mathrm{~mm}$, and the subsidence of the corresponding position in the numerical simulation was $350 \mathrm{~mm}$. As one working face of Yingpanhao mine was $1800 \mathrm{~m}$ in length and the other was $1900 \mathrm{~m}$ in length, both of them were shorter than that of working face in the numerical simulation. Thus, the simulation result was faintly larger than the actual subsidence value. The simulation results were basically consistent with the actual situation, and the established model was reliable.

To study the movement rule of the super-thick and weak cementation overburden in the case of large-scale mining and to grasp the relationship between the mining degree and the surface subsidence coefficient, this paper firstly investigated the surface movement rule of the super-thick and weak cementation overburden in the case of single working face mining (Figure 6). The working face was $300 \mathrm{~m}$ in width.

In Figure 6, with the continuous advancing of working face, the surface subsidence remained increasing. The strike 


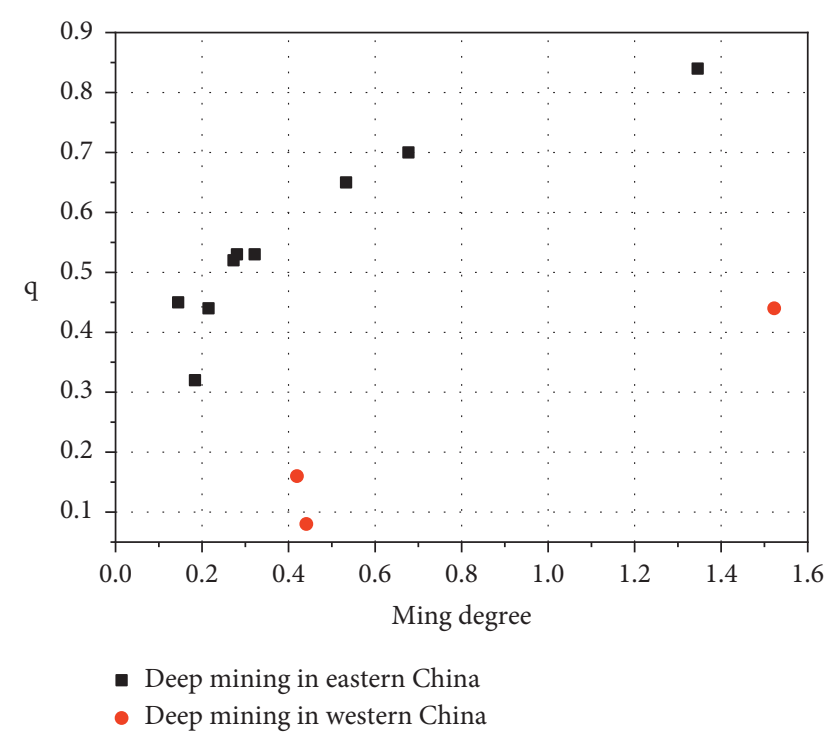

FIGURE 4: Relation of the surface subsidence coefficient and the mining degree.

TABLE 2: Three-dimensional numerical model.

\begin{tabular}{|c|c|c|}
\hline Strata & $\begin{array}{l}\text { Thickness } \\
(\mathrm{m})\end{array}$ & Diagram \\
\hline Loess & 86 & \\
\hline $\begin{array}{l}\text { Sandy mudstone } \\
5\end{array}$ & 27 & \\
\hline $\begin{array}{l}\text { Zhidan group } \\
\text { sandstone }\end{array}$ & 300 & \\
\hline $\begin{array}{l}\text { Coarse } \\
\text { sandstone }\end{array}$ & 14 & \\
\hline $\begin{array}{l}\text { Sandy mudstone } \\
4\end{array}$ & 22 & \\
\hline $\begin{array}{l}\text { Anding group } \\
\text { sandstone }\end{array}$ & 40 & \\
\hline $\begin{array}{l}\text { Anding-Zhiluo } \\
\text { group sandstone }\end{array}$ & 50 & \\
\hline $\begin{array}{l}\text { Zhiluo group } \\
\text { sandstone }\end{array}$ & 120 & \\
\hline $\begin{array}{l}\text { Sandy mudstone } \\
3\end{array}$ & 23 & \\
\hline $\begin{array}{l}\text { Medium } \\
\text { sandstone } 1\end{array}$ & 10 & \\
\hline $\begin{array}{l}\text { Sandy mudstone } \\
2\end{array}$ & 33 & \\
\hline Coal & 6 & \\
\hline $\begin{array}{l}\text { Sandy mudstone } \\
1\end{array}$ & 32 & \\
\hline
\end{tabular}

direction reached full mining, and the surface subsidence was $296 \mathrm{~mm}$ when the working face was $2200 \mathrm{~m}$ in length. It means that in the case of deep single working face mining with the super-thick and weak cementation overburden, the strike direction reached full mining when $D_{3}$ was three times $H_{0}$ or more. $D_{3}$ is the goaf length in the strike direction. $H_{0}$ is the mean mining depth.

To get the mining range that can ensure the full mining of the surface of deep mining with the super-thick and weak cementation overburden fully mine, the law of surface movement in deep multi-working face mining with the super-thick and weak cementation overburden was studied. Table 3 reflects the relationship among the goaf parameters, the mining degree, the surface subsidence coefficient, etc. In Model $B_{1}$, the pillar width is $25 \mathrm{~m}$ and the strike length of the working face is $1500 \mathrm{~m}$. In Model $B_{2}$, the pillar width is $25 \mathrm{~m}$ and the strike length of the working face is $2500 \mathrm{~m}$.

In order to systematically and intuitively analyze the movement and deformation law of deep multi-working face mining, this paper drew the relationship between mining space and surface subsidence coefficient (Figures 7 and 8).

From Figure $7(\mathrm{a})$, when the strike distance is $1500 \mathrm{~m}\left(D_{1} /\right.$ $H_{0}=2$ ), the surface subsidence coefficient increases gradually with the increasing degree of dip mining. The relationship between the dip mining degree and the surface subsidence coefficient is displayed as a Boltzmann function, and the correlation coefficient $\left(R^{2}\right)$ is 0.997 . In Figure 7(b), when the width-depth ratio is 2 , the horizontal movement coefficient decreases gradually with the dip mining degree. There is a sinusoidal relationship between the dip mining degree and the horizontal movement coefficient, and the correlation coefficient is 0.989 . The detailed functional relationship is shown in the following formula:

$$
\left.\begin{array}{l}
b=0.38+0.07 \sin \left(\frac{\pi\left(D_{1} / H_{0}+1.51\right)}{3.65}\right) \\
q=0.73-\frac{0.86}{1+e^{D_{1} / H_{0}-1.20 / 0.72}}
\end{array}\right\} .
$$

According to Figure $8(a)$, when the strike distance is $2500 \mathrm{~m}\left(D_{1} / H_{0}>3\right)$, the surface subsidence coefficient increases gradually with the dip mining degree, and the change rate of the surface subsidence coefficient increases and then decreases. The relationship between the dip mining degree and the surface subsidence coefficient is displayed as a Boltzmann function, and the correlation coefficient is about 0.993. In Figure 8(b), when the width-depth ratio is larger than 3 , the surface horizontal movement coefficient decreases gradually with the dip mining degree. The relationship between dip mining degree and horizontal movement coefficient is sinusoidal, with correlation coefficient of 0.987 . The detailed functional relationship is shown in the following formula:

$$
\left.\begin{array}{l}
b=0.42+0.07 \sin \left(\frac{\pi\left(D_{1} / H_{0}+3.47\right)}{5.03}\right) \\
q=0.87-\frac{0.89}{1+e^{D_{1} / H_{0}-1.03 / 0.31}}
\end{array}\right\} .
$$

In order to study the influence of the strike distance on the surface movement and deformation law of multi-working face mining, this paper obtained the difference of the surface subsidence coefficient and horizontal movement coefficient in Models B1 and B2 under the same dip mining degree (Table 4), and Figure 9 was depicted.

It can be seen from Figure 10(a) that with the dip mining degree, the difference of surface subsidence coefficient 


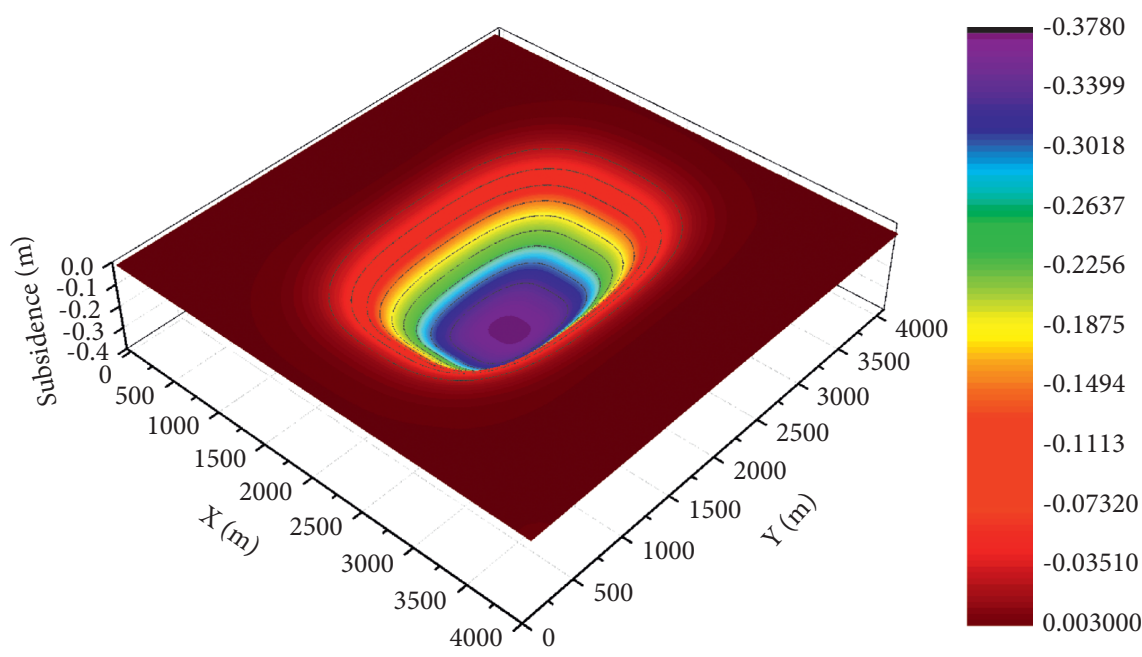

Figure 5: Three-dimensional contour map of surface subsidence.

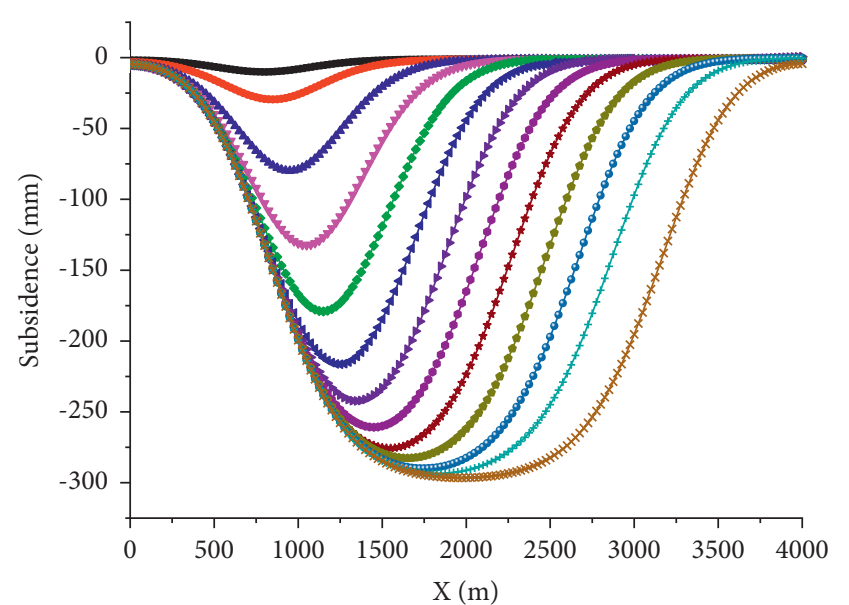

-- Working face advance of $100 \mathrm{~m}$

- W Working face advance of $200 \mathrm{~m}$

— Working face advance of $400 \mathrm{~m}$

$\rightarrow$ Working face advance of $600 \mathrm{~m}$

- Working face advance of $800 \mathrm{~m}$

$\longleftarrow$ Working face advance of $1000 \mathrm{~m}$

$\rightarrow$ Working face advance of $1200 \mathrm{~m}$

$\rightarrow$ Working face advance of $1400 \mathrm{~m}$

* Working face advance of $1600 \mathrm{~m}$

- Working face advance of $1800 \mathrm{~m}$

$\rightarrow$ Working face advance of $2000 \mathrm{~m}$

_- Working face advance of $2200 \mathrm{~m}$

* Working face advance of $2500 \mathrm{~m}$

FIGURE 6: Surface movement rule of single working face mining.

between Models $B_{1}$ and $B_{2}$ first increases, then decreases, and finally approaches to a constant value. The maximum difference of the surface subsidence coefficient is 0.35 , accounting for $76.1 \%$ of the corresponding subsidence coefficient of Model $B_{1}$. The final stable difference of the surface subsidence coefficient is about 0.2 .

In Figure 10(b), with the mining degree, the difference of the horizontal movement coefficient increases gradually and tends to be stable. The maximum difference of the horizontal movement coefficient is about 0.05 , accounting for $16.1 \%$ of the corresponding horizontal movement coefficient in Model $\mathrm{B}_{1}$.

In order to prove Guess 1 mentioned in Section 2, this paper compared the subsidence value of the Zhidan group sandstone with that of the surface (Figure 9). In Figure 9, the Zhidan group sandstone and the surface were bent synchronously when the width-depth ratio in the dip was 0.41 . Because the mining scope was too small, the Zhidan group sandstone was not destroyed. The Zhidan group sandstone and the surface were still bent synchronously when the width-depth ratio in the dip was 0.86 . Although the Zhidan group sandstone was slightly damaged, it could still support the overburden and control the surface deformation at this time. The surface sunk in a fracture manner when the widthdepth ratio in the dip was 1.31. In this case, the Zhidan group sandstone was destroyed, and it could not support the overburden. With the expansion of mining range, the Zhidan group sandstone was further destroyed, and the surface moved downward continuously. These phenomena showed that the Zhidan group sandstone was so strong that it could control the surface movement.

3.2. Energy-Polling Rule of the Super-Thick and Weak Cementation Overburden. The rationale for surface deformation is the overburden failure caused by the mining. In order to deeply study the strata movement rule and to reveal the failure mechanism of deep mining with the super-thick and weak cementation overburden, we deduced the failure pattern by describing the energy distribution rule caused by the mining.

In Figure 11, the energy accumulation was dominated by the compression strain energy when the width-depth ratio in the dip was 0.41 . The compression strain energy in the Zhidan group sandstone was released slightly, and the Zhidan group sandstone was not destroyed. The Zhidan group sandstone and the overburden above it were bent synchronously.

In Figure 12, the compression strain energy was still the main energy accumulation when the width-depth ratio in the 
TABLE 3: Characterization parameters of surface movement and deformation rule in deep multi-working face mining with the super-thick and weak cementation overburden.

\begin{tabular}{|c|c|c|c|c|c|c|c|c|}
\hline $\begin{array}{l}\text { Pillar width } \\
(\mathrm{m})\end{array}$ & $\begin{array}{l}\text { Strike length } \\
(\mathrm{m})\end{array}$ & $\begin{array}{l}\text { Mining width } \\
(\mathrm{m})\end{array}$ & $\begin{array}{l}\text { Width-depth ratio in the } \\
\text { strike }\end{array}$ & $\begin{array}{l}\text { Width-depth ratio in } \\
\text { the dip }\end{array}$ & $\begin{array}{l}W_{\max } \\
(\mathrm{mm})\end{array}$ & $\begin{array}{r}U_{\max } \\
(\mathrm{mm}) \\
\end{array}$ & $q$ & $b$ \\
\hline \multirow{8}{*}{25} & \multirow{8}{*}{2500} & 300 & 3.45 & 0.41 & 295 & 139 & 0.09 & 0.47 \\
\hline & & 625 & 3.45 & 0.86 & 1499 & 691 & 0.3 & 0.46 \\
\hline & & 950 & 3.45 & 1.31 & 3689 & 1596 & 0.61 & 0.43 \\
\hline & & 1275 & 3.45 & 1.76 & 4849 & 2052 & 0.81 & 0.42 \\
\hline & & 1600 & 3.45 & 2.21 & 4899 & 1958 & 0.82 & 0.4 \\
\hline & & 1925 & 3.45 & 2.65 & 5154 & 1975 & 0.86 & 0.38 \\
\hline & & 2250 & 3.45 & 3.1 & 5296 & 1957 & 0.88 & 0.37 \\
\hline & & 2575 & 3.45 & 3.55 & 5400 & 1929 & 0.9 & 0.36 \\
\hline \multirow{8}{*}{25} & \multirow{8}{*}{1500} & 300 & 2.07 & 0.41 & 265 & 120 & 0.08 & 0.45 \\
\hline & & 625 & 2.07 & 0.86 & 1000 & 435 & 0.2 & 0.44 \\
\hline & & 950 & 2.07 & 1.31 & 1942 & 815 & 0.32 & 0.42 \\
\hline & & 1275 & 2.07 & 1.76 & 2748 & 1098 & 0.46 & 0.4 \\
\hline & & 1600 & 2.07 & 2.21 & 3420 & 1283 & 0.57 & 0.38 \\
\hline & & 1925 & 2.07 & 2.65 & 3652 & 1241 & 0.61 & 0.34 \\
\hline & & 2250 & 2.07 & 3.1 & 4001 & 1295 & 0.67 & 0.32 \\
\hline & & 2575 & 2.07 & 3.55 & 4207 & 1306 & 0.7 & 0.31 \\
\hline
\end{tabular}

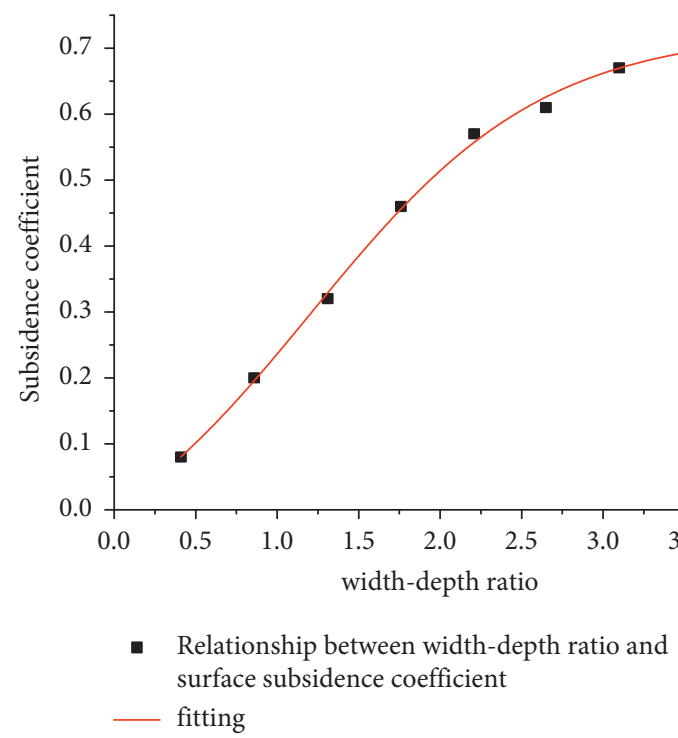

(a)

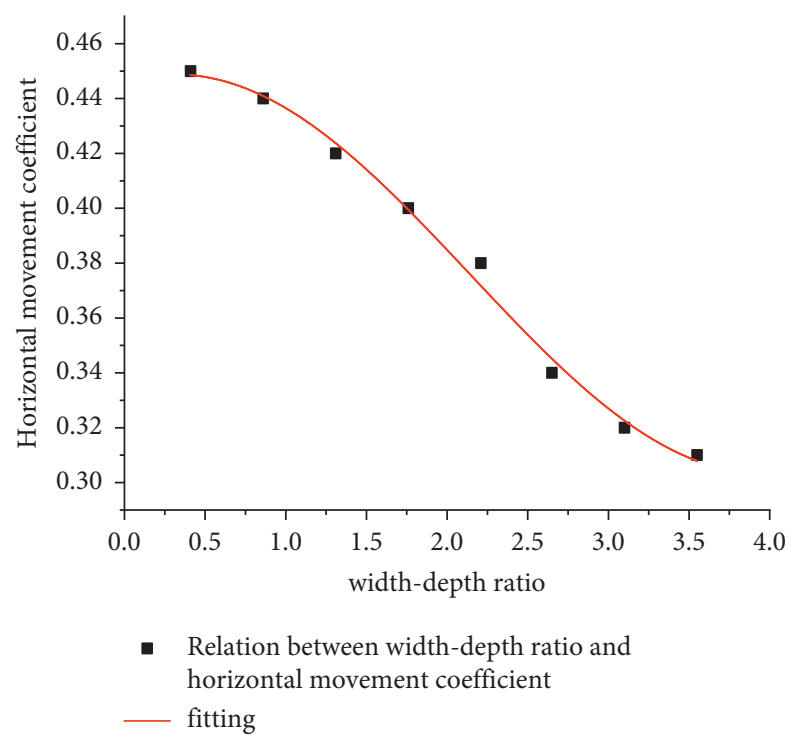

(b)

FiguRE 7: Influence rule of mining space on surface movement and deformation (Model $B_{1}$ ). (a) Influence of mining space on q. (b) Influence of mining space on $b$.

dip was 0.86 . The compression strain energy accumulation occurred in the upper part of the Zhidan group sandstone above the goaf. Because the Zhidan group sandstone was seriously bent, the upper part of it was compressed. At this time, the tensile strain energy occurred in its low part. As the tensile strain energy was small, the Zhidan group sandstone was slightly damaged. The Zhidan group sandstone and the overburden above it were still bent synchronously.

In Figure 13, the large-scale energy accumulation occurred in the Zhidan group sandstone, even in the surface above the goaf when the width-depth ratio in the dip was 1.31. The energy distribution was significantly different from that shown in Figures 12 and 13. These phenomena indicated that the Zhidan group sandstone was destroyed for the first time, and a great deal of energy was released. However, the Zhidan group sandstone and the overburden above it moved violently towards the goaf where they squeezed each other and generated energy accumulation again. In this case, the arch energy dissipation zone appeared in the energy accumulation area of the Zhidan group sandstone. Because the failure pattern of the Zhidan group sandstone was similar to the arch structure, its compressed upper sandstone would lead to the energy accumulation, while there was no squeezing phenomenon inside the arch structure in the Zhidan group sandstone, so no energy accumulation would occur. In this case, the surface sunk in a fracture manner.

In Figure 14, the energy accumulation range in the Zhidan group sandstone and the overburden above it was further 


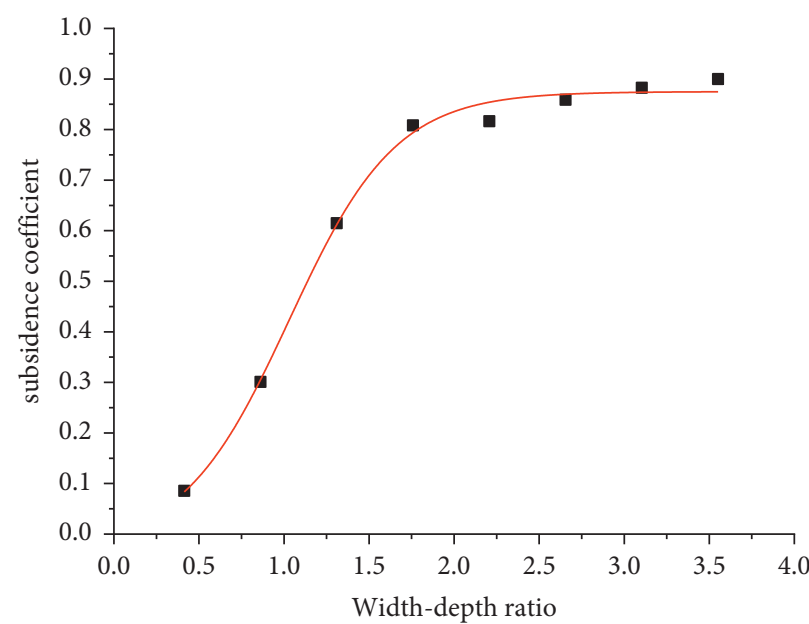

- Relationship between width-depth ratio and surface subsidence coefficient fitting

(a)

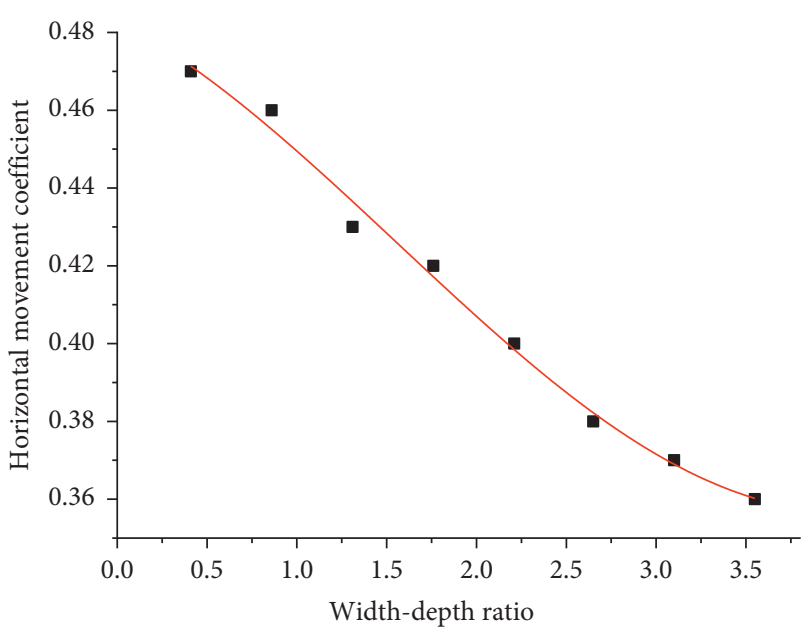

- The relation between width-depth ratio and horizontal movement coefficient - fitting

(b)

FIGURE 8: Influence rule of mining space on surface movement and deformation (Model $B_{2}$ ). (a) Influence of mining space on q. (b) Influence of mining space on b.

TAвLE 4: Differences of surface movement and deformation parameter between Models $B_{1}$ and $B_{2}$.

\begin{tabular}{lcccccccc}
\hline Width-depth ratio & 0.41 & 0.86 & 1.31 & 1.76 & 2.21 & 2.65 & 3.1 & 3.55 \\
\hline Surface subsidence coefficient & 0.01 & 0.1 & 0.29 & 0.35 & 0.25 & 0.25 & 0.21 & 0.2 \\
Horizontal movement coefficient & 0.02 & 0.02 & 0.01 & 0.02 & 0.02 & 0.04 & 0.05 & 0.05 \\
\hline
\end{tabular}
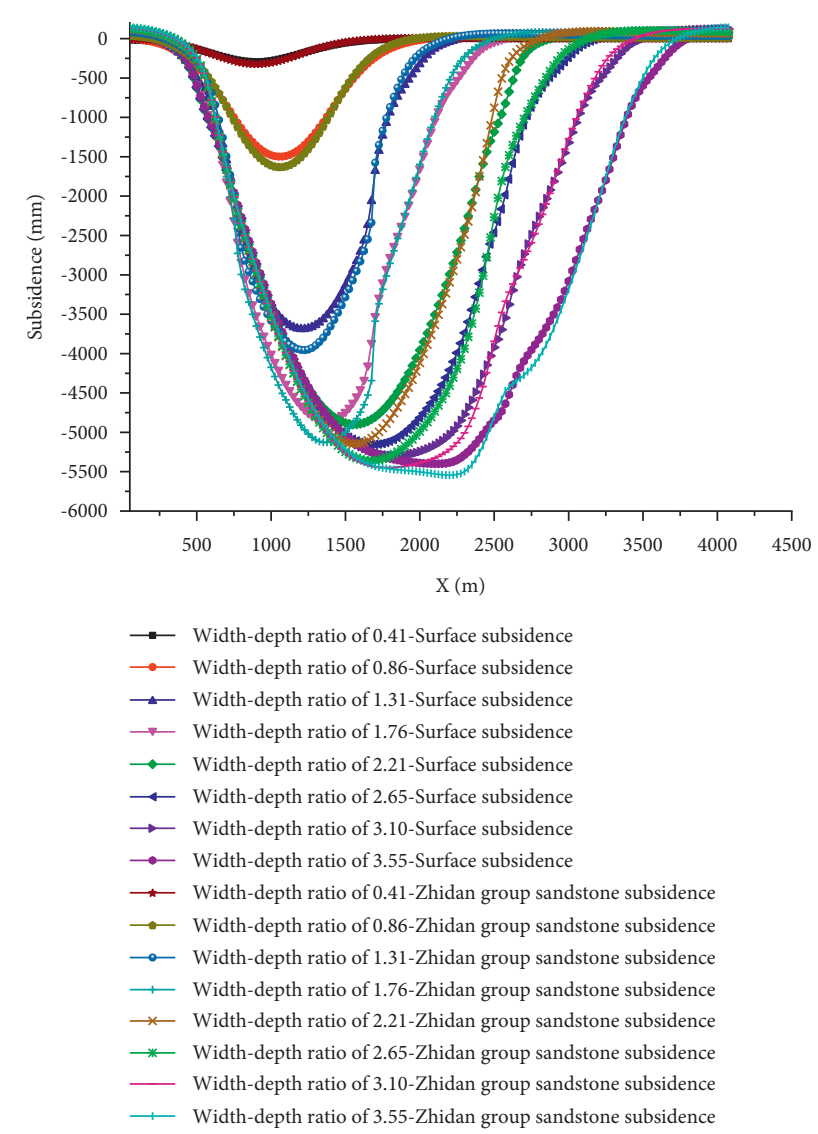

FIGURE 9: Influence of the super-thick weak cementation overburden on the surface movement rule of deep multi-working face mining when $D_{1} / H_{0}>3$. 


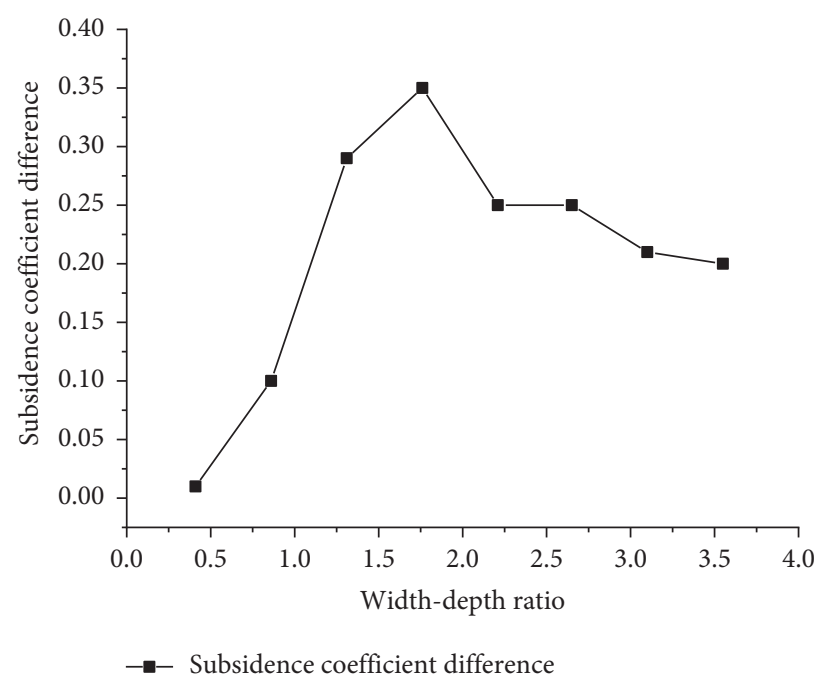

(a)

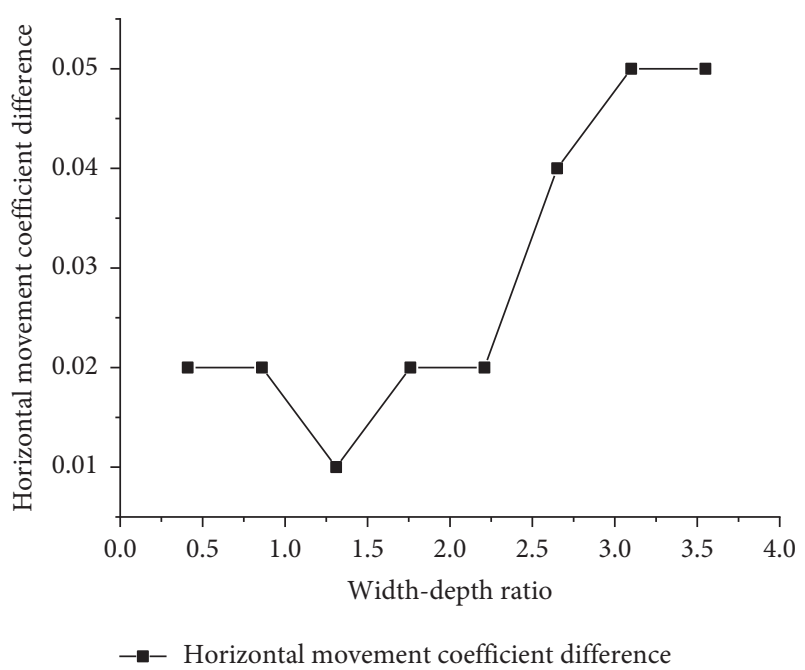

(b)

FIGURE 10: Influence of strike length on surface movement and deformation rule of deep multi-working faces mining. (a) Influence of strike distance on q. (b) Influence of strike distance on b.

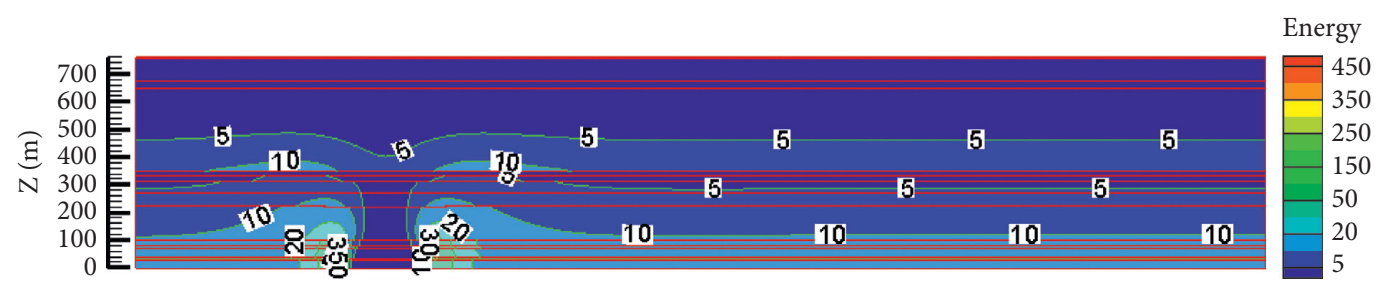

FIGURE 11: Energy distribution after mining the first working face.

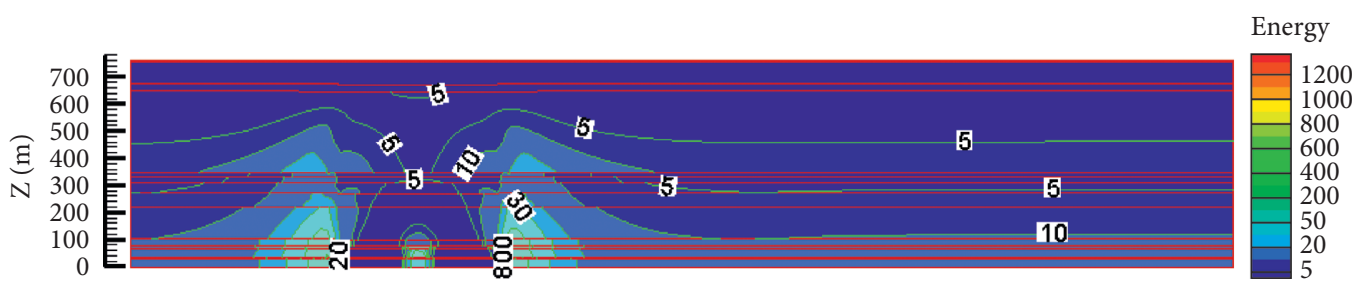

FigURE 12: Energy distribution after mining the second working face.

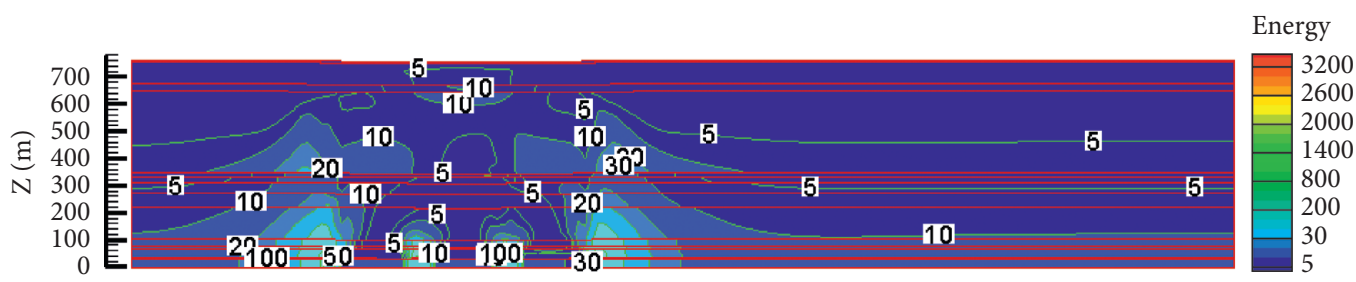

FIGURE 13: Energy distribution after mining the third working face.

expanded, and the scope of the arch energy dissipation zone was narrowed. These phenomena indicated that the Zhidan group sandstone was destroyed ulteriorly, and the Zhidan group sandstone and its overburden moved towards the goaf continuously. The interaction between the strata was more intense, and the interspaces in the overburden were narrowing. In this case, the surface deformation was still active.
In Figure 15, the energy accumulation range in the Zhidan group sandstone and the overburden above it was further expanded, and the arch energy dissipation zone disappeared. It indicated that the movement towards the goaf was continuous in the Zhidan group sandstone and its overburden. The strength of the interaction in the strata was almost at its peak, and the interspaces in the overburden 


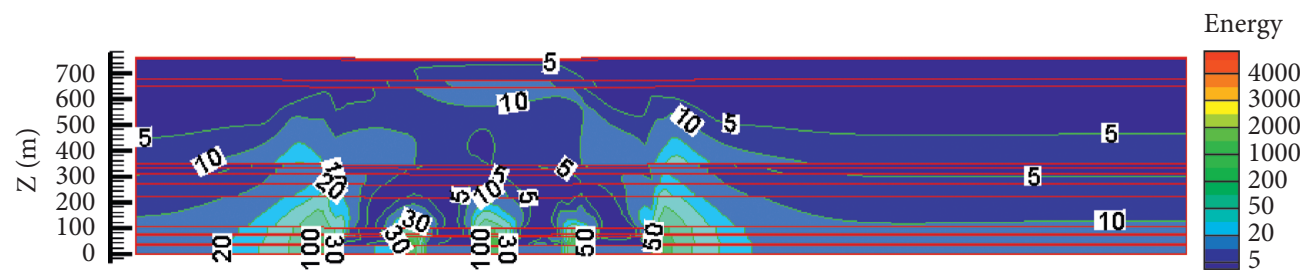

FIgURE 14: Energy distribution after mining the fourth working face.

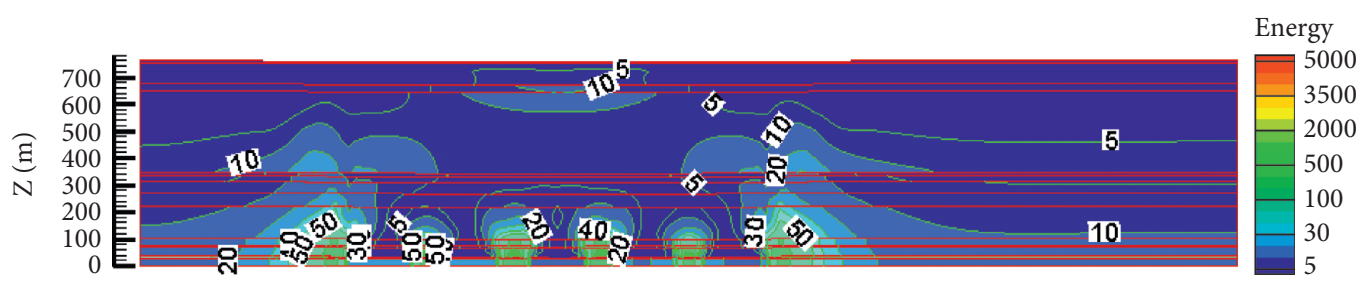

FIGURE 15: Energy distribution after mining the fifth working face.

were closed. In this case, the surface movement was in the recession stage.

Figures 16-18 show that the scope of the energy accumulation in the Zhidan group sandstone and the overburden above it was further expanded, and the scope of the high energy accumulation became smaller and then disappeared. These demonstrated that the movement state of the Zhidan group sandstone and its overburden above the goaf tended to be stable, and the interaction between the strata became weakened. In this case, the sinking basin gradually formed in the surface.

In conclusion, in the case of deep mining with the superthick and weak cementation overburden, there was the inadequate mining characteristics even if the surface reached full mining. The surface reached full mining and the subsidence coefficient was about 0.9 when $D_{1}$ and $D_{3}$ were 3 times $H_{0}$ or more. The Zhidan group sandstone has strong control effect. Its first breaking resulted in the surface sinking in a fractured manner when $D_{1}$ was about 1.3 times $H_{0}$ and $D_{3}$ was 3 times $H_{0}$ or more. The failure pattern of thick Zhidan group sandstone was "arch" failure, which is obviously different from the "beam" failure of hard strata. The failure mode of the super-thick and weak cementation overburden further supported the reliability of the numerical simulation results [20].

\section{Influence of Overburden Characteristics on Strata Movement}

From the above study, we know that both the Zhidan group sandstone and the Jurassic sandstone formations have a certain control effect to the overburden movement. But their working mechanism is not clear. The principal reason resulting in the small surface subsidence of the study area may lie in the joint control effect of the Zhidan group sandstone and the Jurassic thick sandstone formations. In this section, we discuss their role in the overburden movement and the influence of their spatial position in the strata on the overburden movement to understand the interaction mechanism. Four three-dimensional numerical models were established (Figure 19). In Figure 19, the information of the main rock was marked.

In Figure 19, not only the spatial position of the thick sandstone in the strata was changed but also their relative sequence in the strata was reversed. For improving the calculation efficiency of the numerical model, each of these four models was $3000 \mathrm{~m}$ in width, $3000 \mathrm{~m}$ in length, and $763 \mathrm{~m}$ in height. The mining parameters were that working face was $300 \mathrm{~m}$ in width and $1500 \mathrm{~m}$ in length, the coal pillar was $25 \mathrm{~m}$ in width, and five working faces were continuously mined. The numerical simulation results are shown in Figures 20-25 and Tables 5 and 6. One working face is denoted as One-WF. Two working face is denoted as TwoWF. Three working face is denoted as Three-WF. Four working face is denoted as Four-WF. Five working face is denoted as Five-WF.

Based on the simulation results in this section, the distribution of the plastic zone in Model 1 was U-shaped, the plastic zone diffusion in Model 3 was changed from the $\mathrm{U}$ shape to $\mathrm{W}$ shape, and the plastic zone range in Model 3 was wider than that in Model 1 . With the mining of working faces 2201-2205, the difference between the maximum subsidence values of Models 1 and 3 was $190 \mathrm{~mm}, 650 \mathrm{~mm}, 1164 \mathrm{~mm}, 1817 \mathrm{~mm}$, and $1742 \mathrm{~mm}$, respectively. It increased rapidly, which had a positive relationship with the rapid expansion of the plastic zone in the Zhidan group sandstone in Model 3. These phenomena indicated that the failure patterns of the Zhidan group sandstone and the Jurassic sandstone formations were different. The ultimate fracturing length of the Zhidan group sandstone was longer than that of the Jurassic sandstone formations. The control effect of the Zhidan group sandstone was superior to that of the Jurassic sandstone formations.

Based on the simulation results in this section, there was no significant difference in the plastic zone diffusion of Models 3 and 4. In addition, the maximum subsidence of Model 3 was smaller than that of Model 4 in the same mining 


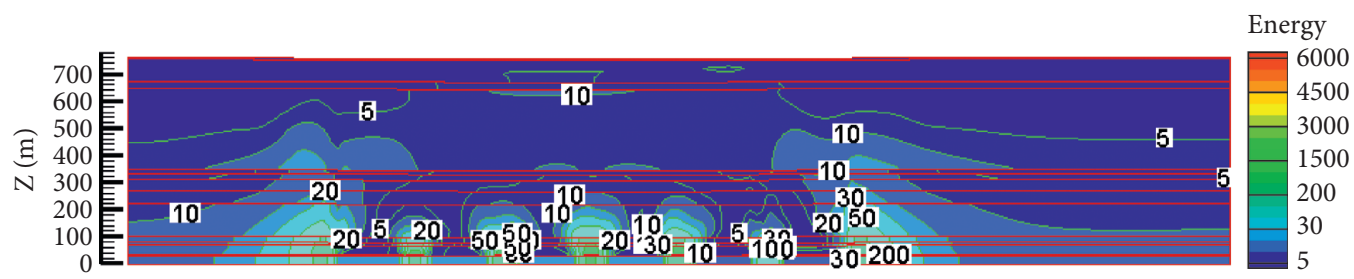

FIGURE 16: Energy distribution after mining the sixth working face.

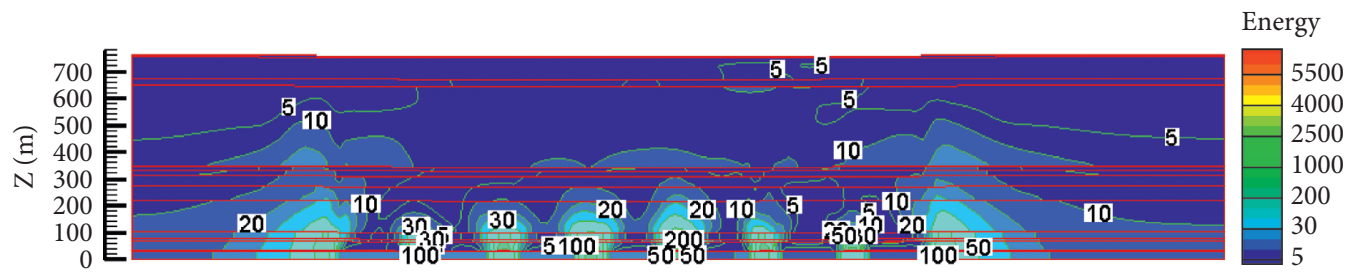

FIGURE 17: Energy distribution after mining the seventh working face.

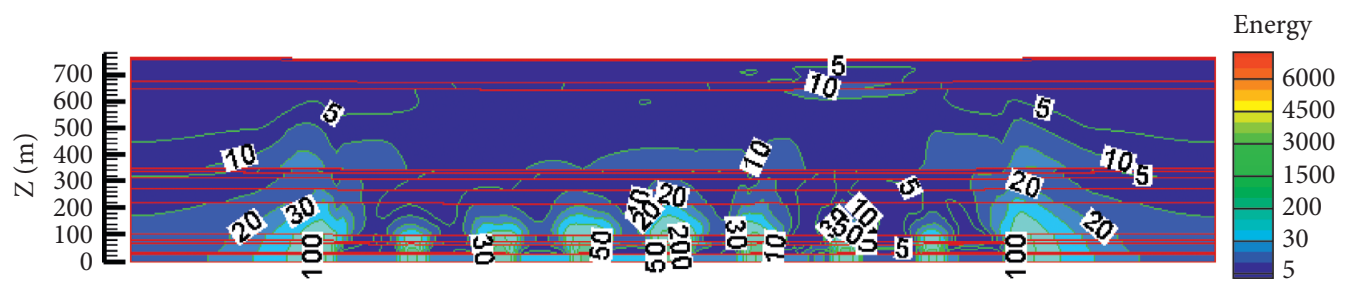

FIgURE 18: Energy distribution after mining the eighth working face.

degree. These phenomena indicated that the control effect of the Jurassic sandstone formations was superior to that of the Zhiluo formation sandstone.

Based on the simulation results in this section, the plastic zone range of Model 2 was wider than that of Model 1 in the same mining degree. With the mining of working faces 2201-2205, the difference between the maximum subsidence values of Models 1 and 2 was $50 \mathrm{~mm}, 249 \mathrm{~mm}, 379 \mathrm{~mm}$, $514 \mathrm{~mm}$, and $516 \mathrm{~mm}$, respectively. There was no significant difference between the plastic zone diffusion of Model 1 and Model 2 because only the spatial position of the thick sandstone in the strata was changed, and their relative sequence in the strata was not reversed.

From the above comparative analysis, it was found that the control effect of the Zhidan group sandstone was superior to that of the Jurassic sandstone formations. The control effect of the Jurassic sandstone formations outdid that of the Zhiluo formation sandstone. Although their relative spatial position had little influence on the overburden movement, their relative sequence had a great influence on the overburden movement. When the Zhidan group sandstone was located above the Jurassic sandstone formations, the Jurassic sandstone formations effectively hindered the damage speed of the overburden and larger mining space was required to destroy the Zhidan group sandstone and to make the surface reach full mining. When the Jurassic sandstone formations were located above the Zhidan group sandstone, the Zhidan group sandstone was rapidly destroyed with the expanded mining range, which resulted in the surface being fully mined. Therefore, the relative sequence of the strong-control and the secondary-control strata in the overburden directly determines the failure pattern of the overburden and is the main factor to affect the overburden movement. The relative spatial position of the strong-control and the secondary-control strata in the overburden has little influence on the failure pattern of the overburden and is the secondary factor to affect the overburden movement.

\section{Discussion}

Due to the strong control effect of the Zhidan group sandstone, the surface subsidence value is small when the goaf is large, and much strain energy accumulates in the overburden. When the goaf range increases to a certain extent, the Zhidan group sandstone will be destroyed. The surface will sink in a fractured manner releasing a lot of the strain energy, which will lead to the occurrence of rock burst, mine earthquake, and other accidents. These seriously threaten the safety of mining workers. Through similar material model, we also got a similar result [20].

In Figure 26, with the mining of working faces 2203 and 2204 , the moving range of the overburden of similar material model expanded, and the coal pillars between working faces 2201 and 2202 and working faces 2202 and 2203 lost the 


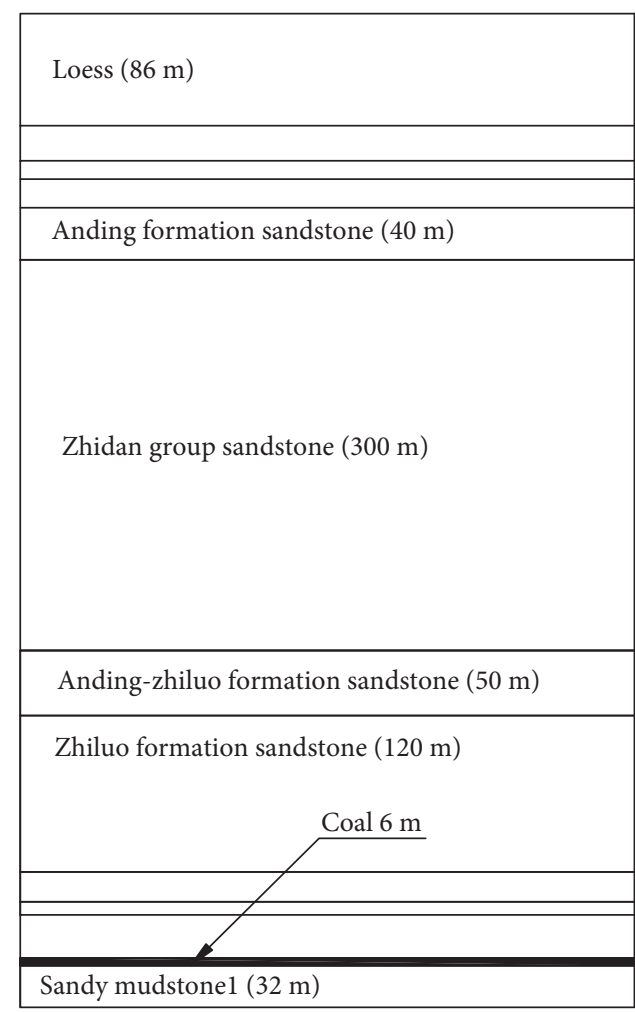

(a)

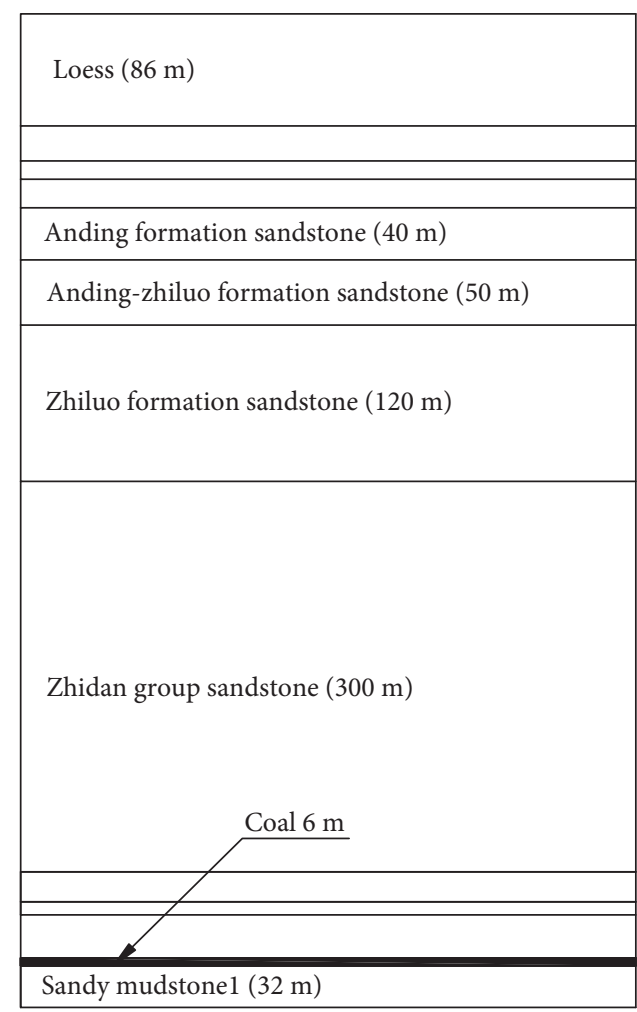

(c)

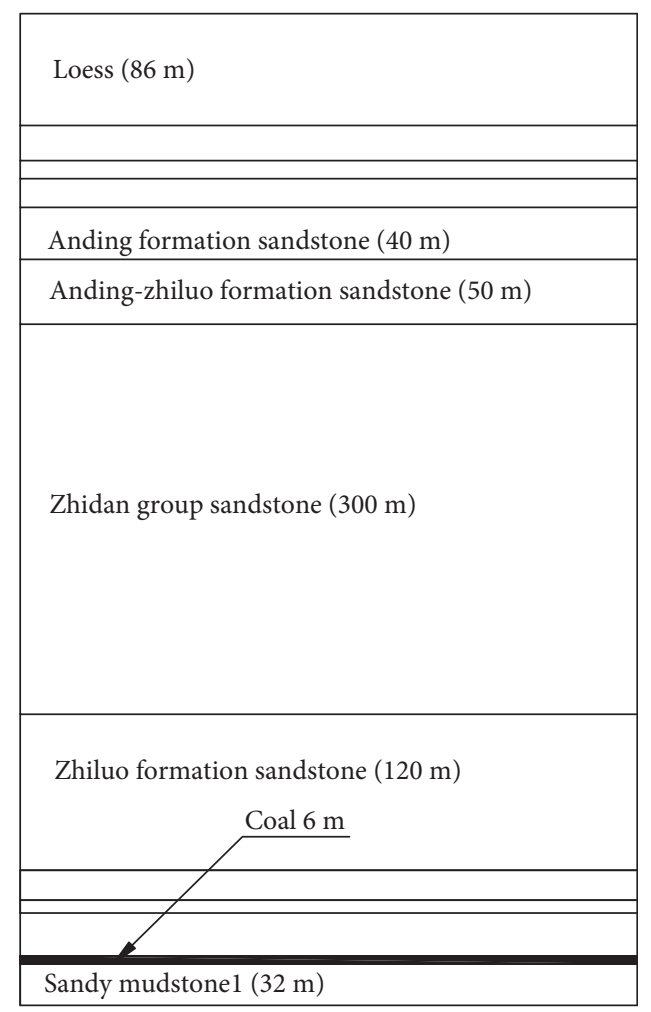

(b)

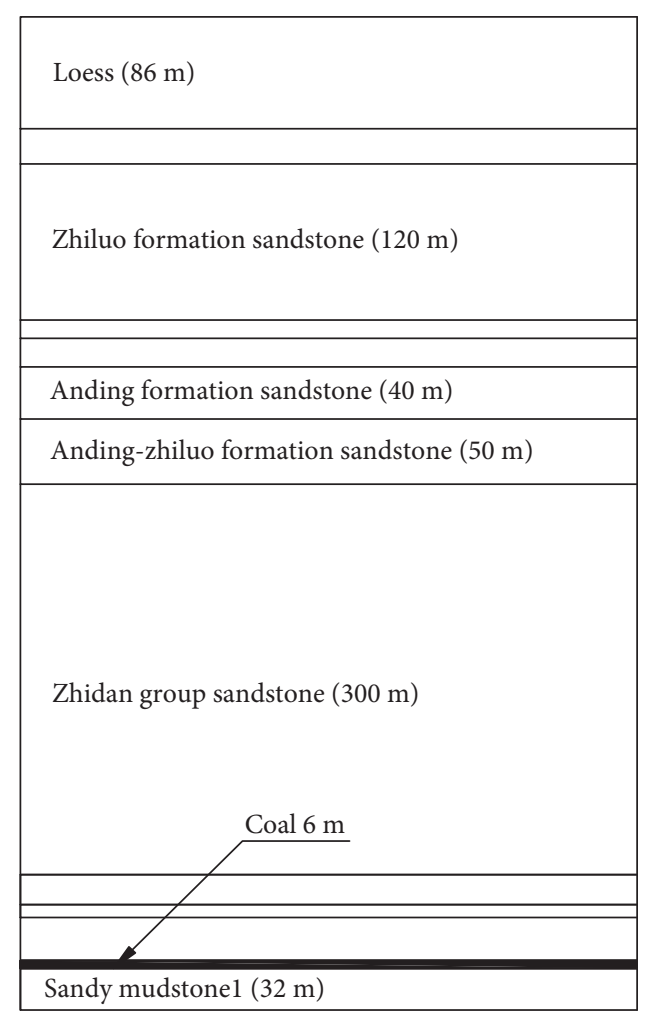

(d)

Figure 19: Schematic diagram of the strata position. (a) Model 1. (b) Model 2. (c) Model 3. (d) Model 4. 


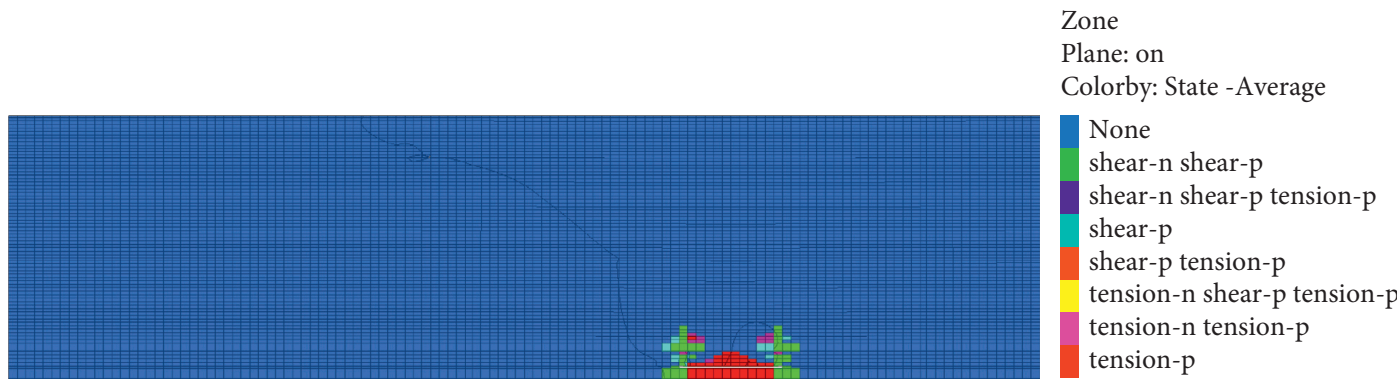

(a)

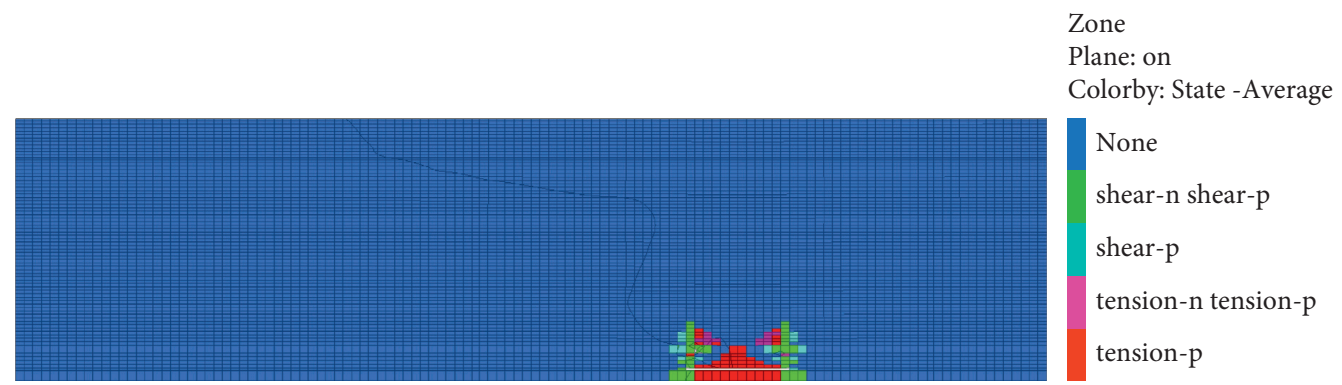

(b)

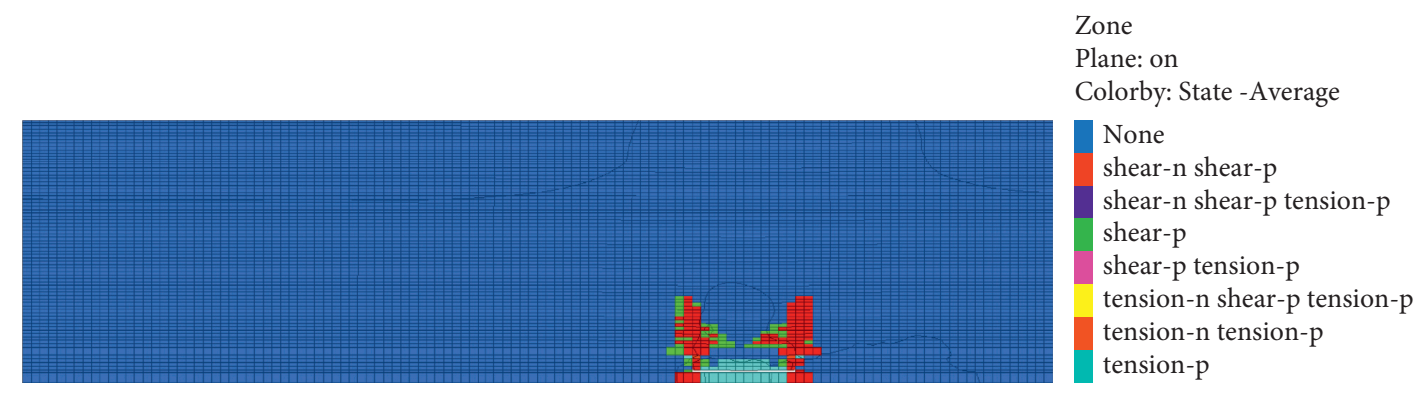

(c)

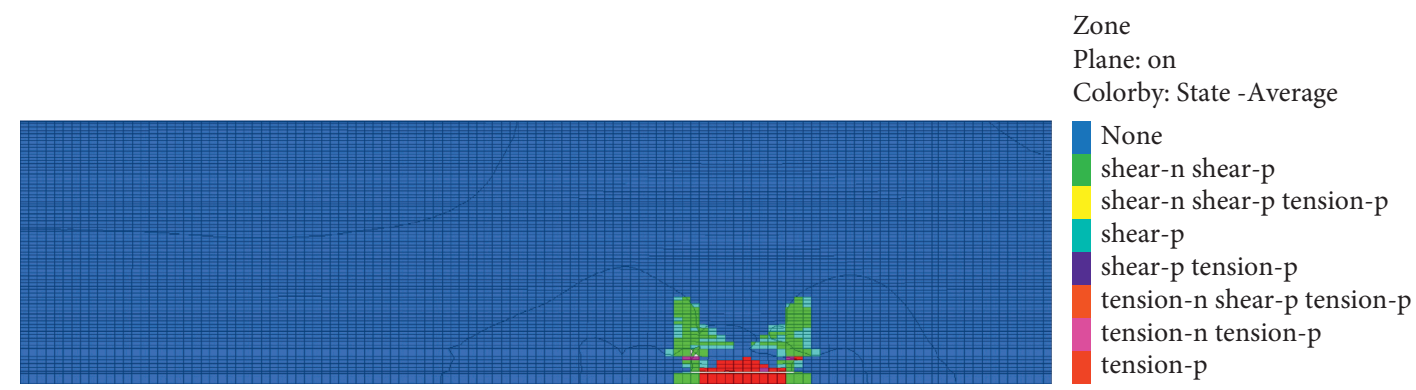

(d)

FIgURE 20: Plastic zone distribution after mining the first working face (working face 2201). (a) Model 1. (b) Model 2. (c) Model 3. (d) Model 4.

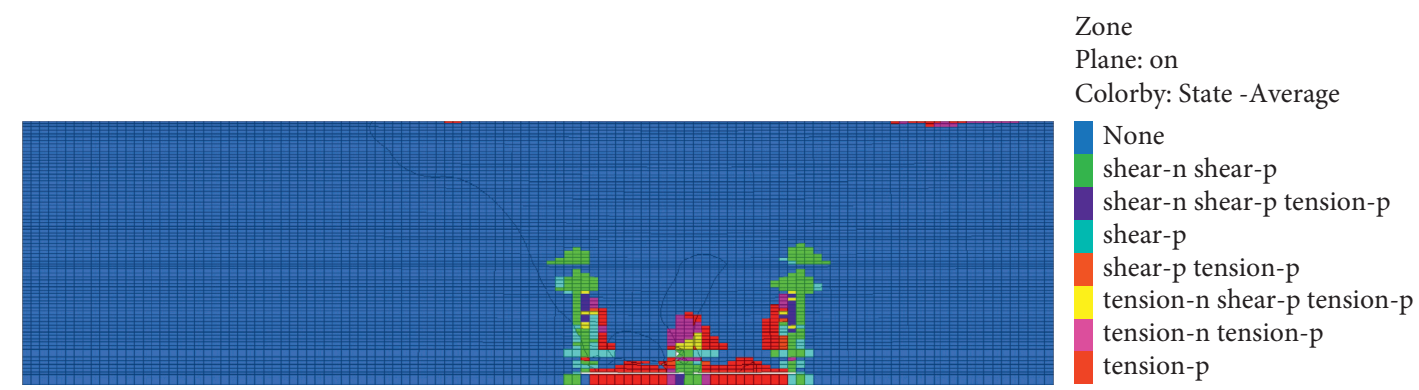

(a)

FIgURE 21: Continued. 


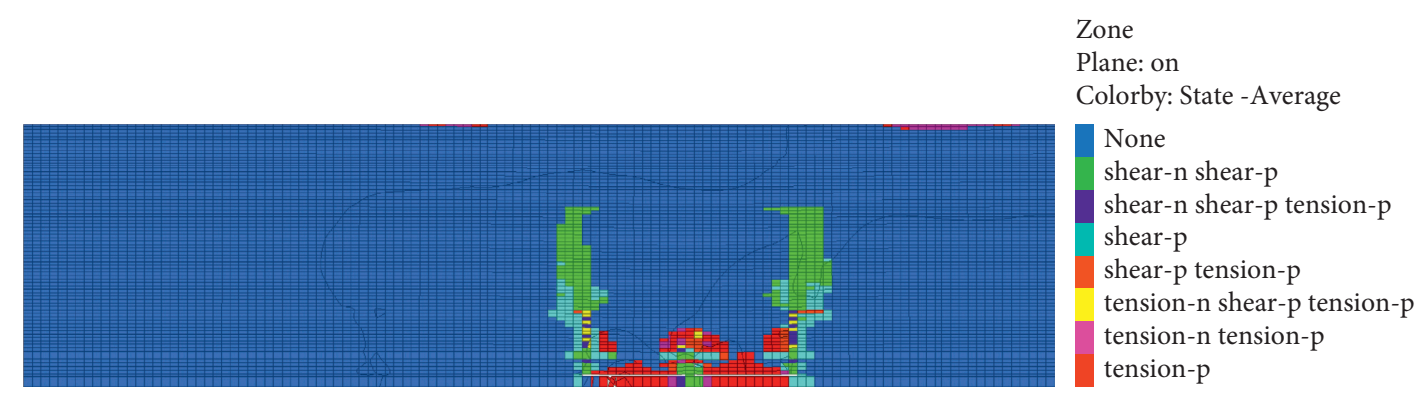

(b)

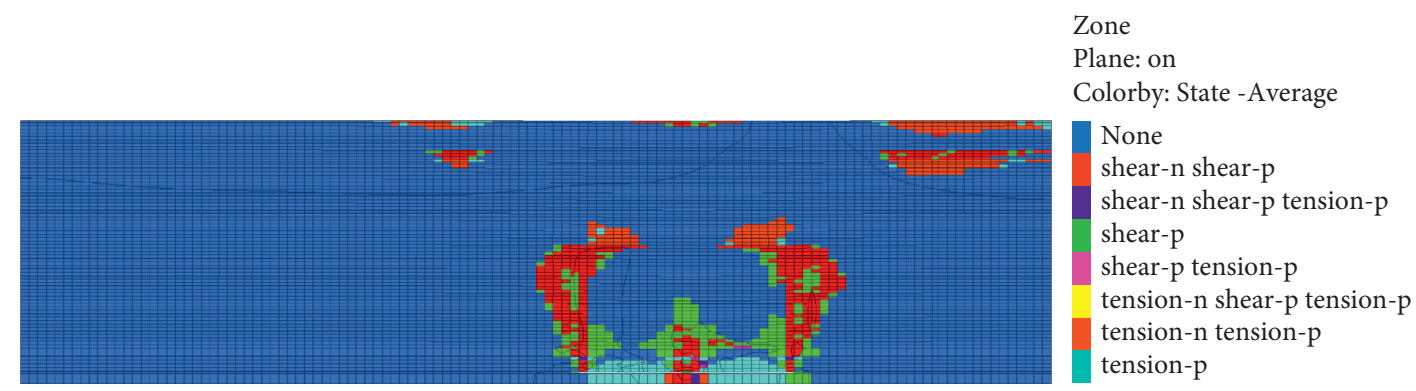

(c)

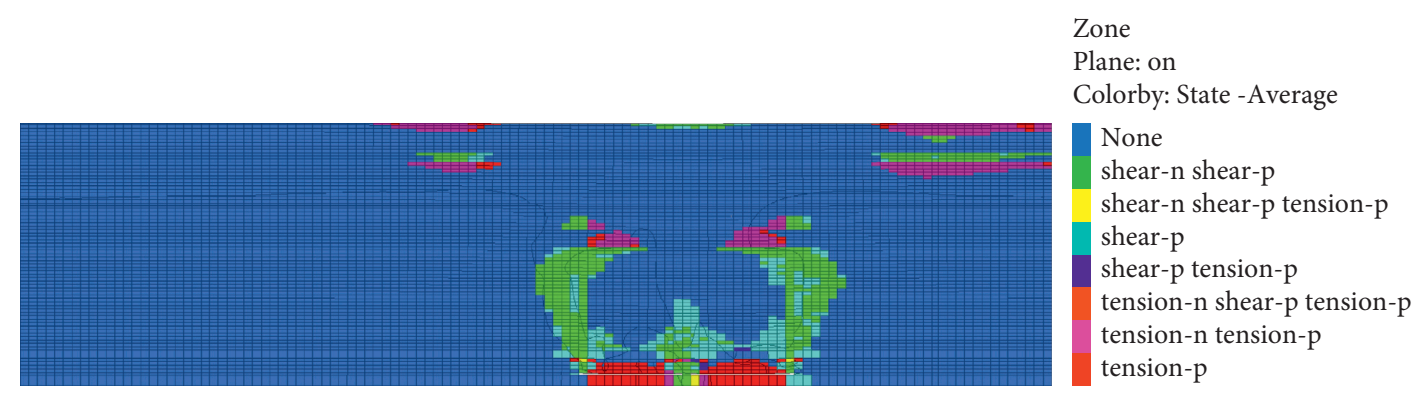

(d)

Figure 21: Plastic zone distribution after mining the second working face (working face 2202). (a) Model 1. (b) Model 2. (c) Model 3. (d) Model 4.

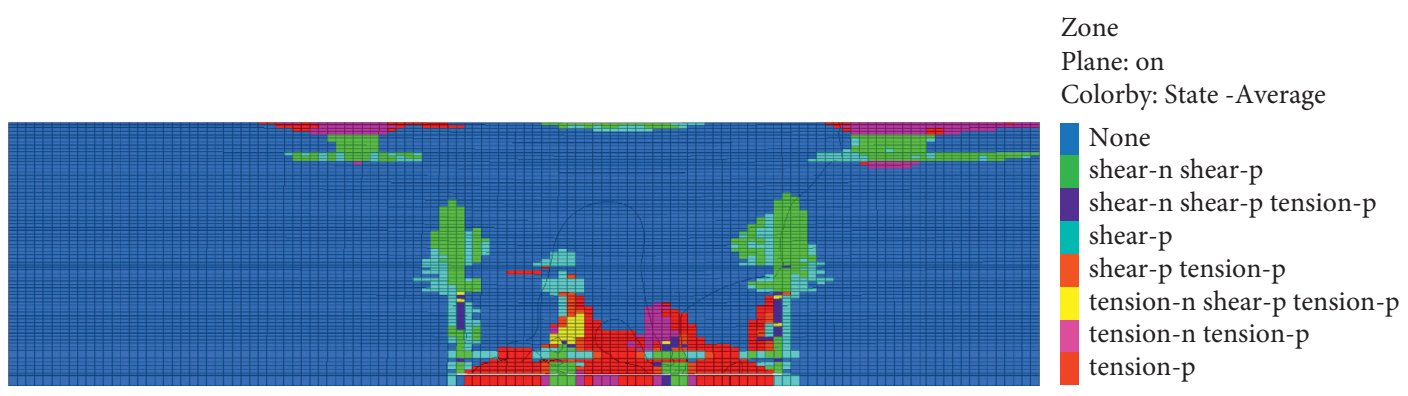

(a)

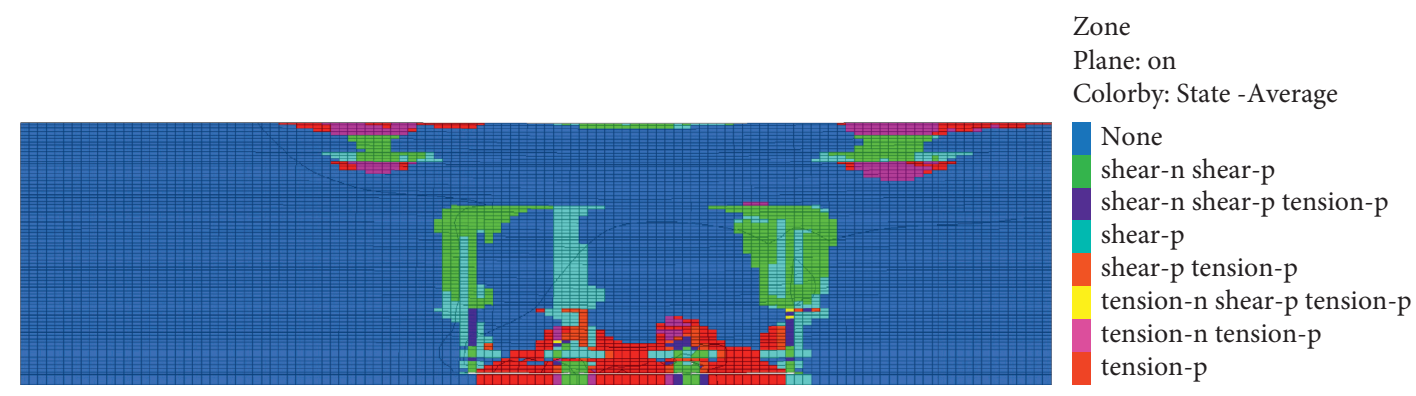

(b)

FIgURE 22: Continued. 


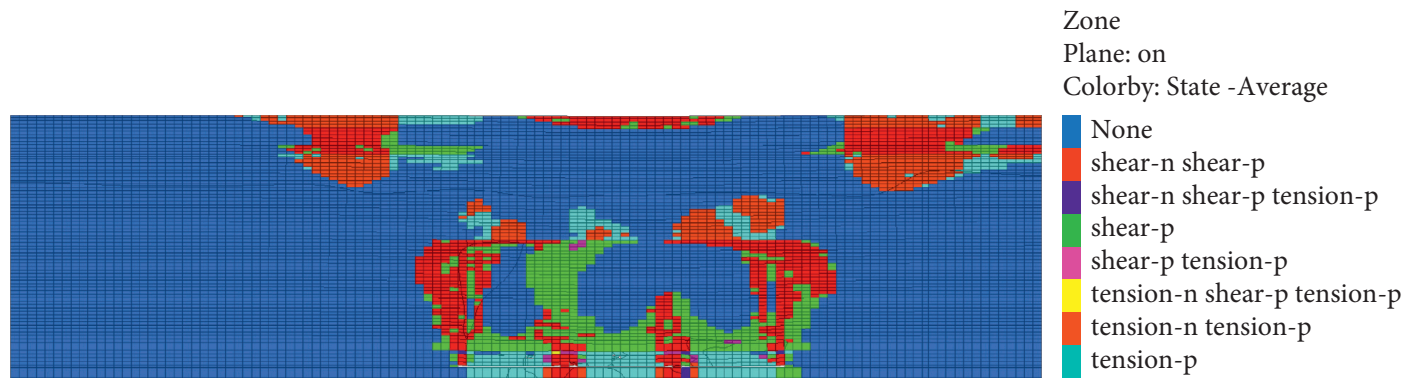

(c)

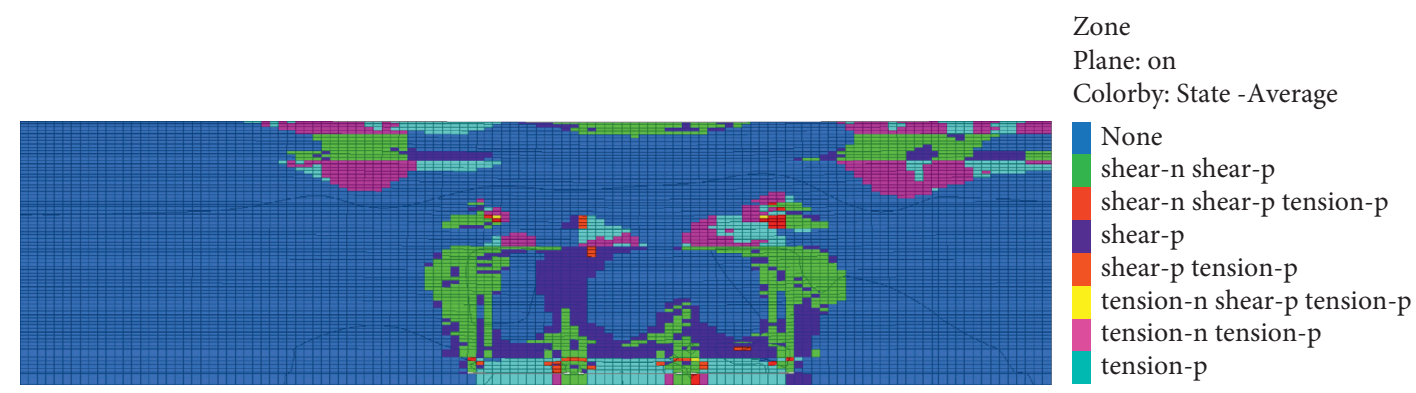

(d)

Figure 22: Plastic zone distribution after mining the third working face (working face 2203). (a) Model 1. (b) Model 2. (c) Model 3. (d) Model 4.

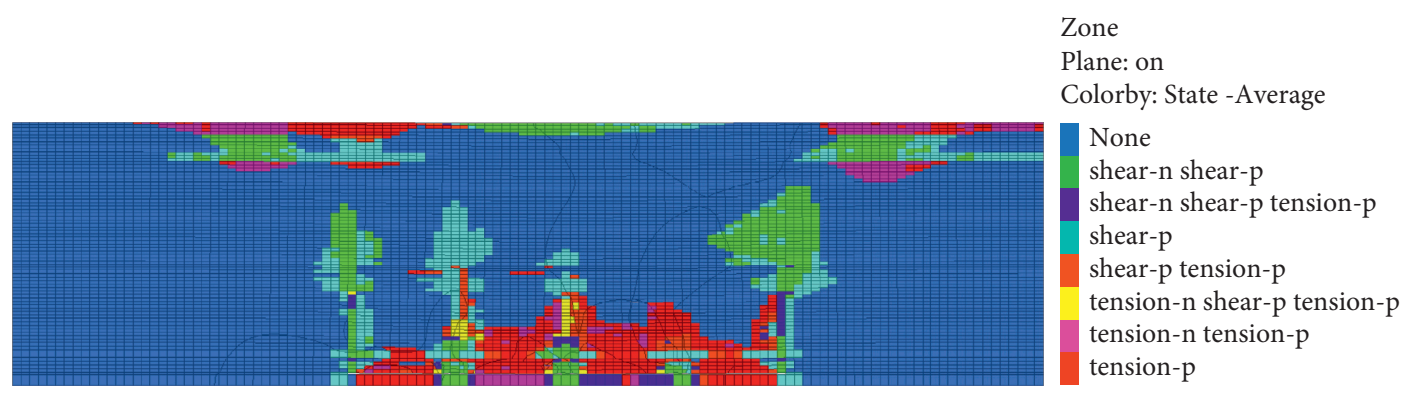

(a)

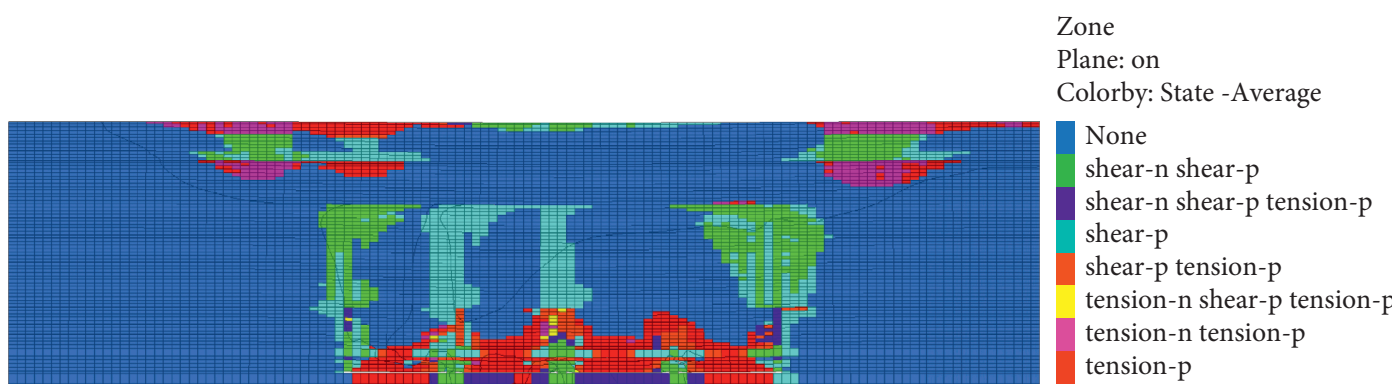

(b)

Zone

Plane: on

Colorby: State -Average

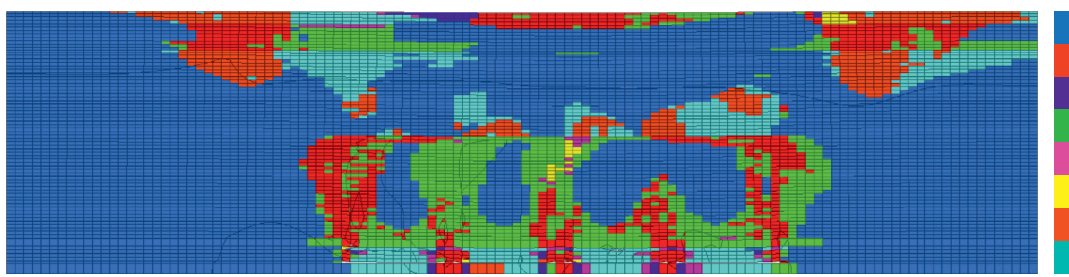

None

shear-n shear-p

shear-n shear-p tension-p

shear-p

shear-p tension- $p$

tension- $n$ shear-p tension-p

tension- $n$ tension- $\mathrm{p}$

(c)

tension-p

Figure 23: Continued. 


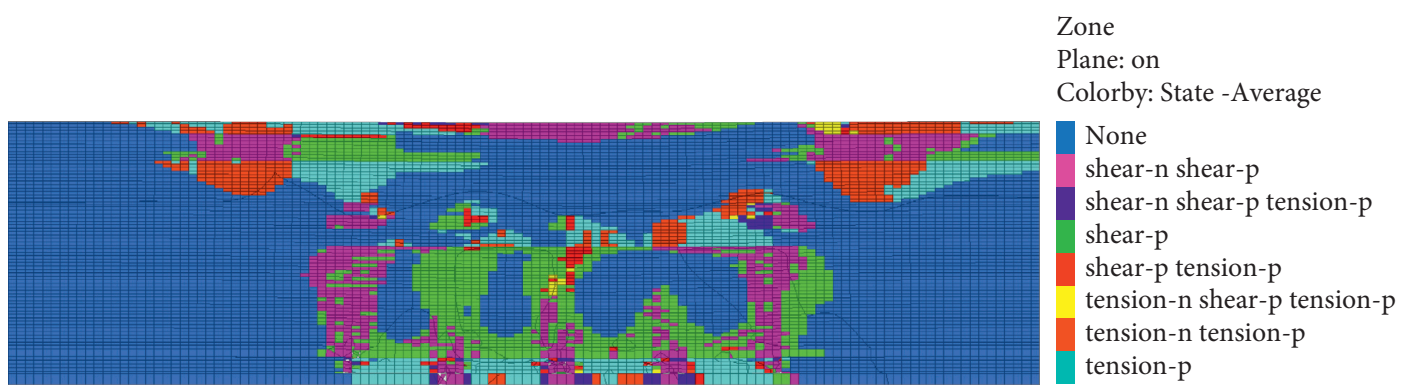

(d)

Figure 23: Plastic zone distribution after mining the fourth working face (working face 2204). (a) Model 1. (b) Model 2. (c) Model 3. (d) Model 4.

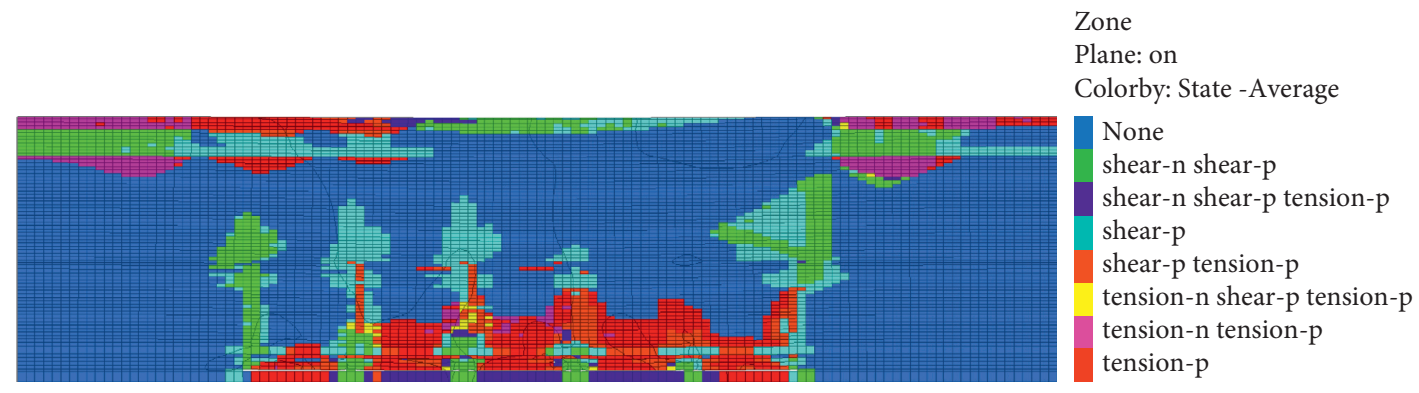

(a)

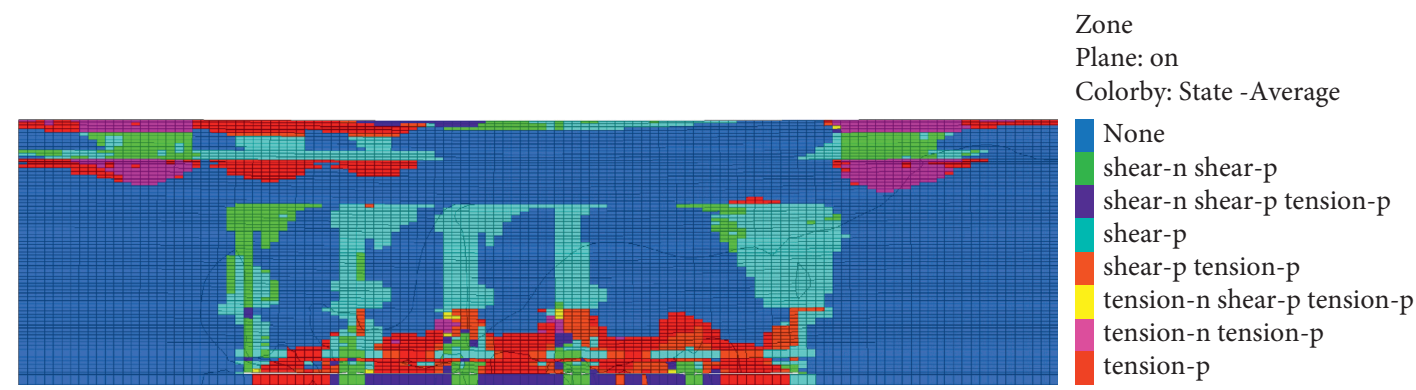

(b)

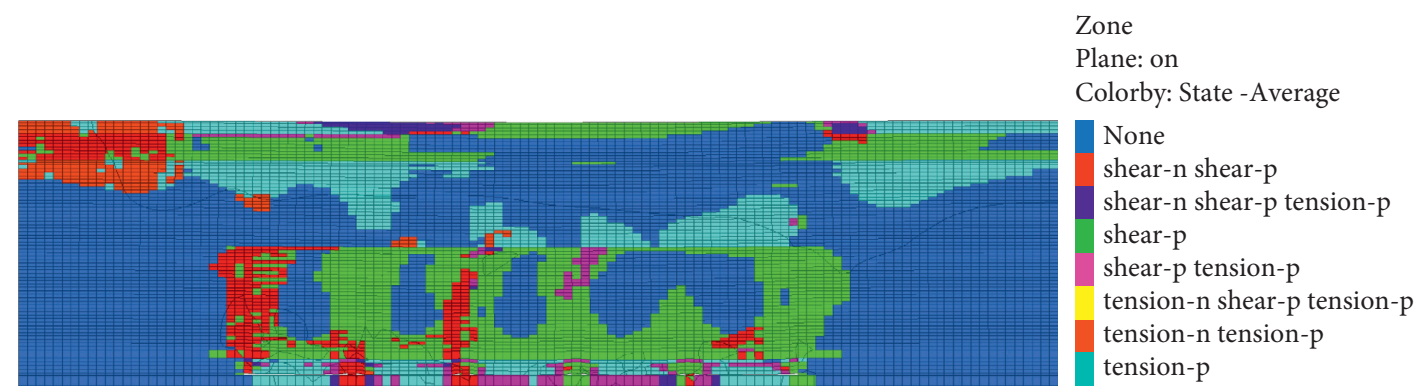

(c)

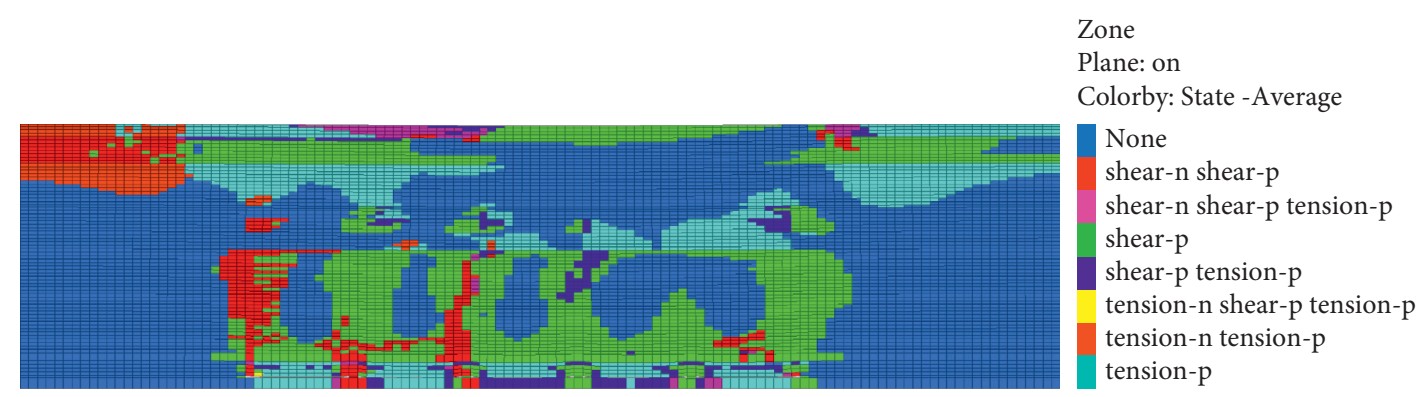

(d)

Figure 24: Plastic zone distribution after mining the fifth working face (working face 2205). (a) Model 1. (b) Model 2. (c) Model 3. (d) Model 4. 


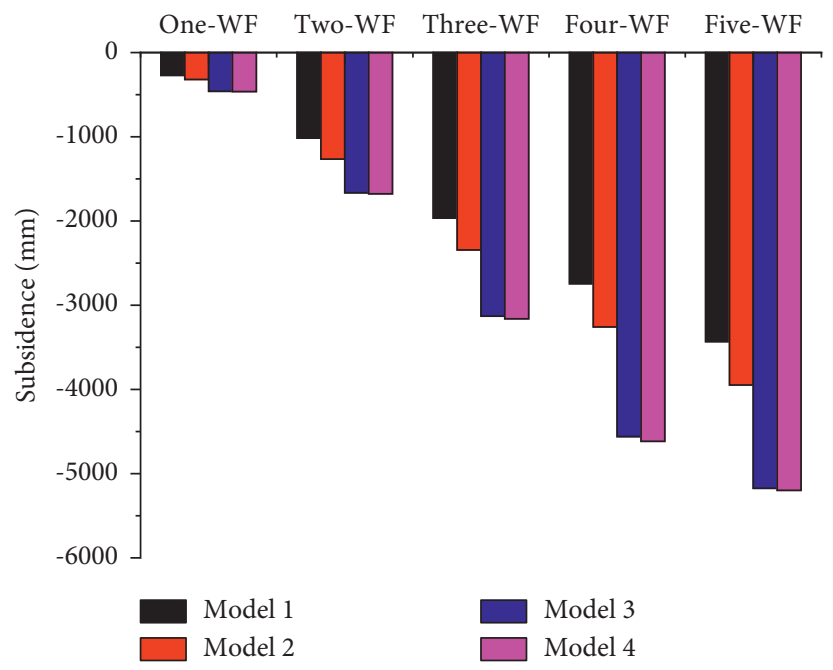

Figure 25: Comparison analysis of the maximum subsidence values in these models.

TABle 5: Proportion of plastic zone in the model.

\begin{tabular}{lccccc}
\hline Model & One working face (\%) & Two working faces (\%) & Three working faces (\%) & Four working faces (\%) & Five working faces (\%) \\
\hline Model 1 & 1.36 & 4.55 & 14.45 & 28.20 & 40.66 \\
Model 2 & 1.59 & 6.20 & 19.95 & 33.75 & 42.77 \\
Model 3 & 2.61 & 10.65 & 29.95 & 44.41 & 48.03 \\
Model 4 & 2.62 & 11.28 & 31.14 & 45.84 & 49.22 \\
\hline
\end{tabular}

TABle 6: Maximum surface subsidence of these models (mm).

\begin{tabular}{lccccc}
\hline Model & One working face & Two working faces & Three working faces & Four working faces & Five working faces \\
\hline Model 1 & -269 & -1015 & -1965 & -2743 & -3432 \\
Model 2 & -320 & -1264 & -2344 & -3258 & -3948 \\
Model 3 & -459 & -1665 & -3129 & -4560 & -5174 \\
Model 4 & -463 & -1677 & -3162 & -4616 & -5199 \\
\hline
\end{tabular}

bearing capacity because of their instability and failure. However, the coal pillar between the 2203 and 2204 working faces was still in a stable state and restricted the overburden to move downward. Therefore, the shape of the $\mathrm{X}$ observation line was like a "w."

Based on the physical simulation, it could be found that the first breaking span of the immediate roof reached $120 \mathrm{~m}$, the cyclic fracturing length was about $60 \mathrm{~m}$, and the first weighting interval and the cyclic weighting interval were much larger than the those of the middle hard overburden in the Carboniferous Permian coal seam in the eastern mining area of China. The height of the caving zone was about $33 \mathrm{~m}$, and the height of the water suture zone was about $112 \mathrm{~m}$, which was noticeably larger than that of the middle hard and weak overburden in Central China and Eastern China. The Zhidan group sandstone and the Jurassic sandstone formations had a certain control effect on the overburden movement.

In this paper, we reveal the failure mechanism of the super-thick and weak cementation overburden and basically grasp the space-time evolution rule of its movement and its failure characteristics, which has an important reference to control the failure of the super-thick and weak cementation overburden and the surface movement. Although this paper has done some work on the movement rule and failure mechanism of the super-thick and weak cementation overburden, there are still the following deficiencies. (1) The surface measurement data are not sufficient. The surface measurement data of deep large-scale mining with the super-thick and weak cementation overburden are not available. Relevant data will be continuously collected to optimize the research results. (2) The research results of this paper only refer to the geological and mining conditions of Yingpanhao mine, and the study area is too small. Relevant data of other deep mines with super-thick and weak cementation overburden will be constantly collected to optimize the research results.

So far, the national filling mining technology has been relatively mature, which has a significant effect in the control of rock movement. In the future research, we will focus on designing a reasonable filling mining plan to effectively control the damage of the super-thick and weak cementation overburden while rationally utilizing the waste rocks in the working face. 


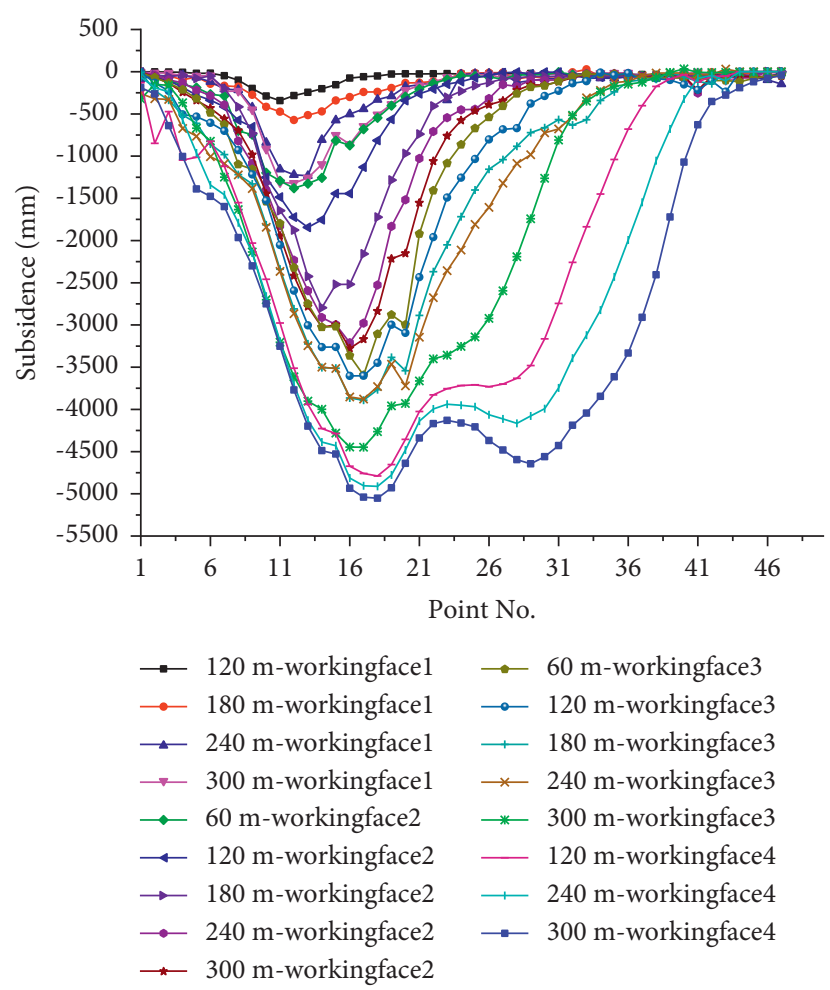

Figure 26: Subsidence curve of observation line X during mining.

\section{Conclusions}

In this paper, based on the measurement results in the field, we analyzed the differences of the surface movement rule of deep mining between the middle hard overburden in Eastern China and the super-thick and weak cementation overburden in Western China. Then, we applied the numerical simulation method to deeply study the surface movement rule and the influence of overburden characteristics on strata movement and revealed the failure mechanism of the superthick and weak cementation overburden. The following findings were obtained:

(1) Under the same mining degree, the surface subsidence coefficient of deep mining with the super-thick and weak cementation overburden in Western China is much smaller than that of deep mining with the middle hard overburden in Eastern China. It shows the particularity which is seriously inconsistent with the weak lithology of the weak cementation overburden.

(2) It still shows the characteristics of the inadequate mining when the surface reaches full mining. The surface reaches full mining and the subsidence coefficient is about 0.9 when $D_{1}$ and $D_{3}$ are 3 times $H_{0}$ or more. The relationships of the dip mining degree, the surface subsidence coefficient, and the dip mining degree, the horizontal movement coefficient, are displayed as Boltzmann and sinusoidal functions.

(3) The Zhidan group sandstone has strong control effect. Its first breaking results in surface sinking in a fractured manner when $D_{1}$ is about 1.3 times $H_{0}$ and $D_{3}$ is 3 times $H_{0}$ or more. The failure pattern of thick Zhidan group sandstone is "arch" failure, which is obviously different from the "beam" failure of hard strata.

(4) The control effect of the Zhidan group sandstone is superior to that of the Jurassic sandstone formations. The control effect of the Jurassic sandstone formations is above that of the Zhiluo formation sandstone.

(5) The relative sequence of the strong-control and the secondary-control strata in the overburden is the main factor to affect the overburden movement. The relative spatial position of the strong-control and the secondary-control strata in the overburden is the secondary factor to affect the overburden movement.

This paper deeply investigates the surface movement rule of deep large-scale mining with the super-thick and weak cementation overburden, explores the reasons for the specialty of the overburden movement, and reveals the failure mechanism of the super-thick and weak cementation overburden. It has great potential applications and scientific significance in green mining, environment-damage control, and scientific mining of deep resources with the ultrathick and weak cementation overburden.

\section{Data Availability}

The data used to support the findings of this study are available from the corresponding author upon request. 


\section{Disclosure}

Sifeng Zhang and Guojian Zhang are the first and second corresponding authors, respectively.

\section{Conflicts of Interest}

The authors declare that there are no conflicts of interest regarding the publication of this paper.

\section{Acknowledgments}

The authors gratefully acknowledge the financial support from the National Natural Science Foundation of China (grant no. 51974292) and the Open Research Fund of Coal Industry Engineering Research Center of Collaborative Monitoring of Mining Area's Environment and Disasters (grant no. KSXTJC202002).

\section{References}

[1] Q. Meng, L. Han, W. Qiao, D. Lin, and J. Fan, "Support technology for mine roadways in extreme weakly cemented strata and its application," International Journal of Mining Science and Technology, vol. 24, no. 2, pp. 157-164, 2014.

[2] V. A. Eremenko, L. N. Gakhova, and E. N. Semenyakin, "Formation of higher stress zones and clusters of seismic events in deep mining in Tashtagol," Journal of Mining Science, vol. 48, no. 2, pp. 269-275, 2012.

[3] X. Chen, W. Li, and X. Yan, "Analysis on rock burst danger when fully-mechanized caving coal face passed fault with deep mining," Safety Science, vol. 50, no. 4, pp. 645-648, 2012.

[4] E. T. Brown, "Progress and challenges in some areas of deep mining," Mining Technology, vol. 121, no. 4, pp. 177-191, 2012.

[5] T. Jiřina and Š. Jan, "Reduction of surface subsidence risk by fly ash exploitation as filling material in deep mining areas," Natural Hazards, vol. 53, pp. 251-258, 2010.

[6] R. C. W. Webber, R. M. Franz, W. M. Marx, and P. C. Schutte, "A review of local and international heat stress indices, standards and limits with reference to ultra-deep mining," Journal of the South African Institute of Mining and Metallurgy, vol. 103, pp. 313-323, 2003.

[7] X. C. Wang, Z. Yue, X. G. Jiang, and Z. Peng, "A dynamic prediction method of deep mining subsidence combines D-InSAR technique," Procedia Environmental Sciences, vol. 10, pp. 2533-2539, 2011.

[8] V. N. Oparin, I. I. Ainbinder, Y. I. Rodionov et al., "Concept of a mine of tomorrow for deep mining at gentle copper-andnickel deposits," Journal of Mining Science, vol. 43, no. 6, pp. 646-654, 2007.

[9] J. Gao and G. Bai, "Rules and mechanism of surface subsidence in deep coal mining," in Proceedings of the 2015 international academic forum for mine surveying in china, Beijing, China, October 2015.

[10] X. Wang, On Analysis of Surface Subsidence Rule for DeepMining, Shanxi Architecture, Taiyuan, China, 2015.

[11] D. R. Cope, "Deep mining of coal and land-use planning: technical change and technical competence," Minerals and the Environment, vol. 4, no. 2-3, pp. 105-110, 1982.

[12] J. Z. Wang and Y. Zhang, "Study on the relation of the mining degree and the surface subsidence coefficient," Mine Surveying, vol. 4, pp. 10-13, 1996.
[13] Y. Wang, Z. X. Tan, and P. X. Li, "Research on the subsidence rule of deep mining in 1-km ming," Coal Science and Technology, vol. 6, pp. 1-4, 2013.

[14] L. G. Zhang, Overburden Failure Mechanism and Surface Movement Law Due to Sub-critical Extraction in Yanzhou Mining Area, China University of Mining and Technology, Xuzhou, China, 2009.

[15] P. X. Li, Study on Regularity and Prediction Method of Surface Subsidence Due to Deep Mining-Taking Xuzhou Coal Mining Area as Example, China University of Mining and Technology, Xuzhou, China, 2012.

[16] Y. Fan and C. Shuang, "Numerical simulation of compound media coupling mechanism of deep mining overburden strata," Transactions of Nonferrous Metals Society of China, vol. 21, pp. s631-s636, 2011.

[17] W.-X. Li, L. Wen, and X.-M. Liu, "Ground movements caused by deep underground mining in Guan-Zhuang iron mine, Luzhong, China," International Journal of Applied Earth Observation and Geoinformation, vol. 12, no. 3, pp. 175-182, 2010.

[18] F. J. Yang, "Actual measurement of overlying strata and surface movement of full-mechanized caving mining under extremely-thick cretaceous sandstone aquifer," Coal Mining Technology, vol. 19, pp. 95-97, 2014.

[19] X. Y. Yu, J. J. Liu, W. B. Guo and W. Q. Xu, Surveying of surface movement rule with giant thick cretaceous sandstone," Coal Mining Technology, vol. 14, pp. 15-17, 2016.

[20] G. Zhang, G. Guo, Y. N. Lv, and Y. Gong, "Study on the strata movement rule of the ultrathick and weak cementation overburden in deep mining by similar material simulation: a case study in China," Mathematical Problems in Engineering, vol. 2020, Article ID 7356740, 21 pages, 2020. 